\title{
Potential of Trichoderma spp. for Biocontrol of Aflatoxin-Producing Aspergillus flavus
}

\author{
Xianfeng Ren ${ }^{1,2, \dagger}$, Maria Teresa Branà ${ }^{3, \dagger}$, Miriam Haidukowski ${ }^{3 \oplus}$, Antonia Gallo ${ }^{4}$, Qi Zhang ${ }^{5}$, \\ Antonio F. Logrieco ${ }^{4}$, Peiwu Li ${ }^{5}$, Shancang Zhao ${ }^{1,2, *}$ and Claudio Altomare ${ }^{3, *}$ (i)
}

1 Institute of Agricultural Quality Standards and Testing Technology, Shandong Academy of Agricultural Sciences, Jinan 250100, China; renxianfenga@163.com

2 Shandong Provincial Key Laboratory of Test Technology on Food Quality and Safety, Jinan 250100, China

3 Institute of Sciences of Food Production, National Research Council, 70126 Bari, Italy; mariateresabrana@gmail.com (M.T.B.); miriam.haidukowski@ispa.cnr.it (M.H.)

4 Institute of Sciences of Food Production, National Research Council, 73100 Lecce, Italy; antonia.gallo@ispa.cnr.it (A.G.); antonio.logrieco@ispa.cnr.it (A.F.L.)

5 Oil Crops Research Institute, The Chinese Academy of Agricultural Sciences, Wuhan 430062, China; zhangqi01@caas.cn (Q.Z.); peiwuli@oilcrops.cn (P.L.)

* Correspondence: zhbszhaoshancang@shandong.cn (S.Z.); claudio.altomare@ispa.cnr.it (C.A.); Tel.: +86-27-868-12943 (S.Z.); +39-80-592-9318 (C.A.)

+ These authors contributed equally to this work.

check for updates

Citation: Ren, X.; Branà, M.T.; Haidukowski, M.; Gallo, A.; Zhang, Q.; Logrieco, A.F.; Li, P.; Zhao, S.; Altomare, C. Potential of Trichoderma spp. for Biocontrol of Aflatoxin-Producing Aspergillus flavus. Toxins 2022, 14, 86. https:// doi.org/10.3390/toxins14020086

Received: 23 December 2021

Accepted: 18 January 2022

Published: 23 January 2022

Publisher's Note: MDPI stays neutral with regard to jurisdictional claims in published maps and institutional affiliations.

Copyright: (C) 2022 by the authors. Licensee MDPI, Basel, Switzerland. This article is an open access article distributed under the terms and conditions of the Creative Commons Attribution (CC BY) license (https:// creativecommons.org/licenses/by/ $4.0 /)$.

\begin{abstract}
The inhibitory action of 20 antagonistic Trichoderma isolates against the aflatoxigenic isolate A. flavus ITEM 9 (Af-9) and their efficacy in reducing aflatoxin formation in vitro were examined. Production of metabolites with inhibitory effect by the Trichoderma isolates was also investigated. Antagonistic effect against Af- 9 was assessed by inhibition of radial growth of the colonies and by fungal interactions in dual confrontation tests. A total of 8 out of 20 isolates resulted in a significant growth inhibition of 3-day-old cultures of Af- 9 , ranging from $13 \%$ to $65 \%$. A total of 14 isolates reduced significantly the aflatoxin $\mathrm{B}_{1}\left(\mathrm{AfB}_{1}\right)$ content of 15 -day-old Af- 9 cultures; 4 were ineffective, and 2 increased $A B_{1}$. Reduction of $A_{f B}$ content was up to $84.9 \%$ and $71.1 \%$ in 7 - and 15-dayold cultures, respectively. Since the inhibition of Af- 9 growth by metabolites of Trichoderma was not necessarily associated with inhibition of $\mathrm{AfB}_{1}$ production and vice versa, we investigated the mechanism of reduction of $\mathrm{AfB}_{1}$ content at the molecular level by examining two strains: one (T60) that reduced both growth and mycotoxin content; and the other (T44) that reduced mycotoxin content but not Af-9 growth. The expression analyses for the two regulatory genes aflR and aflS, and the structural genes aflA, aflD, aflO and aflQ of the aflatoxin biosynthesis cluster indicated that neither strain was able to downregulate the aflatoxin synthesis, leading to the conclusion that the $\mathrm{AfB}_{1}$ content reduction by these Trichoderma strains was based on other mechanisms, such as enzyme degradation or complexation. Although further studies are envisaged to identify the metabolites involved in the biocontrol of $A$. flavus and prevention of aflatoxin accumulation, as well as for assessment of the efficacy under controlled and field conditions, Trichoderma spp. qualify as promising agents and possible alternative options to other biocontrol agents already in use.
\end{abstract}

Keywords: Trichoderma; biocontrol; Aspergillus flavus; aflatoxin; secondary metabolites

Key Contribution: Six out of twenty Trichoderma spp. isolates showed a marked antagonistic behavior against an aflatoxigenic strain of Aspergillus flavus, and sixteen out of twenty isolates produced metabolites that inhibited aflatoxin $\mathrm{B}_{1}$ production by 9 to $100 \%$. Reduction of aflatoxin amount did not appear to be due to downregulation of either regulatory or structural genes of aflatoxin biosynthesis, but to lesser growth of A. flavus or conceivably to other mechanisms, such as degradation or modification of aflatoxin molecule. 


\section{Introduction}

Aflatoxins are a group of potent mycotoxins produced by moulds of the genus Aspergillus in the course of spoilage of agricultural products, stored commodities, feeds and foods. Among the different forms of aflatoxins, aflatoxins $B_{1}, B_{2}, G_{1}$ and $G_{2}$ are especially important [1], since they exhibit carcinogenic, mutagenic and hepatotoxic effects [2]. The most potent form is aflatoxin $B_{1}\left(A_{f} B_{1}\right)$, which is classified as carcinogenic to humans (group I) by the International Agency for Research on Cancer [3,4]. The main aflatoxigenic species is Aspergillus flavus [5], a saprophytic soil fungus with a large degree of genetic diversity, hundreds of different vegetative compatibility groups [6] and morphologically variable types, distinguished into two morphotypes based on sclerotia size, i.e., Group I (S strains) with sclerotia $<400 \mu \mathrm{m}$ in diameter and Group II (L strains) with sclerotia $>400 \mu \mathrm{m}$ in diameter [7]. L strains produce aflatoxins $B_{1}$ and $B_{2}$, are quite variable in the levels of aflatoxin produced and also include non-producing strains (non-aflatoxigenic strains). Conversely, $\mathrm{S}$ strains show less variation in aflatoxin production, are generally higher aflatoxin producers than $L$ strains and can produce aflatoxins $G_{1}$ and $G_{2}$ in addition to aflatoxins $B_{1}$ and $B_{2}$ [8]. Another important aflatoxigenic species is $A$. parasiticus, which is able to produce all four of the above aflatoxins. Aspergillus flavus and A. parasiticus differ in host range and habitat. Aspergillus flavus occurs more widely on cereals, oilseeds and dried fruits, including economically important crops, such as peanuts and corn [9-11], while A. parasiticus is more strictly associated with soil environment and infections of belowground plant organs [12].

The occurrence of aflatoxins in foods and feeds is a major economic and food safety issue worldwide. Due to the danger to human and animal health, aflatoxins are highly regulated in most countries in the world, although regulations are not harmonized. To protect humans and animals from exposure to aflatoxins, the US Food and Drug Administration has set a limit of $20 \mu \mathrm{g} / \mathrm{kg}$ (ppb) of total aflatoxins in food and feed [13]; in China, according to the National Standards on Mycotoxins Limit in Food, the limits for $\mathrm{AfB}_{1}$ are $20 \mu \mathrm{g} / \mathrm{kg}$ in peanut, $10 \mu \mathrm{g} / \mathrm{kg}$ in rice and $5 \mu \mathrm{g} / \mathrm{kg}$ in wheat and related cereals [14]. In the European Union, the guidelines are more strict, setting a limit of $8 \mu \mathrm{g} / \mathrm{kg} \mathrm{AfB} \mathrm{Af}_{1}$ in food and $0.1 \mu \mathrm{g} / \mathrm{kg}$ $\mathrm{AfB}_{1}$ in cereal-based foods for babies and young children [15]. According to the Rapid Alert System for Food and Feed reports [16], in the last ten years $A_{f B}$ has been a frequent cause of rejection of imported products, leading to severe economic losses, especially for developing countries [17].

Aflatoxin-producing Aspergillus spp. generally infect plants in the field, leading to contamination of crops with aflatoxins at harvest and further aflatoxin accumulation under storage if temperature and humidity are not controlled properly [18]. Infections and aflatoxin contamination are more severe under plant-stressing climatic conditions, such as high heat and drought $[19,20]$, thus the climate change and global warming are expected to increase the risk of aflatoxin occurrence in temperate areas in the years to come. In this scenario, management of aflatoxigenic fungi at pre-harvest becomes a fundamental part of a multiple action strategy to reduce the risk of aflatoxins at consumption [18]. Good cultural practices, such as balanced watering and fertilization, which reduce plant stress and injuries caused by pests, have mitigating effects on $A$. flavus infections and aflatoxin occurrence. However, these practices are not always possible or sufficient to lower the infections of A. flavus and aflatoxin formation to acceptable levels. The development of cultivars that are less subjected to $A$. flavus infections or aflatoxin biosynthesis still encounters major hurdles, including a lack of resistant genotypes in some crop species (e.g., cotton), the long time required for breeding programs and questionable stability of the resistance conferred by the currently available genes [21], while transgenic approaches are not universally accepted.

Studies on the genetic and aflatoxigenic diversity in A. flavus and on the dynamics of $A$. flavus populations of high and low aflatoxin-producing genotypes sharing the same niche have led to the development of a biological control strategy based on competitive exclusion [18,22]. The biocontrol relies on the inundative introduction of atoxigenic strains that are incapable of producing aflatoxins because they either lack necessary aflatoxin 
biosynthesis genes or have deleterious mutations in critical biosynthesis genes [23]. The atoxigenic $A$. flavus strains, once spread on the soil surface, with time displace the native aflatoxigenic genotypes by a mechanism of competition [22,24]. Currently, this strategy is being intensively studied and applied in an attempt to replace existing methods of chemical control, which may leave toxic residues or lead to development of resistant biotypes of the pathogen [25]. Nevertheless, the use of non-aflatoxigenic strains is not without drawbacks [26,27]. Aspergillus flavus is a heterothallic fungus, capable of sexual reproduction between individuals with different mating type loci (Mat1-1 and Mat1-2). Recombination can occur during sexual crosses and has also been detected between aflatoxigenic and non-aflatoxigenic strains. Therefore, the possibility exists that the capability to produce aflatoxins is transferred to the progeny of atoxigenic strains. In addition, other toxic metabolites on top of aflatoxins may be produced by A. flavus, including cyclopiazonic acid, aflatrem, aflavinines, paxillines, paspalicines and pseurotin [28,29]. These mycotoxins are not regulated and are not tracked by surveillance programs, but epidemiological data suggest that they might exert toxic effects on their own or act synergistically with aflatoxins [30,31]. Since the biosynthesis of those toxins is genetically regulated independently of aflatoxins, the non-aflatoxigenic biocontrol strains might still be capable of producing one or more of these other mycotoxins. Finally, it should be noted that, while the biocontrol $A$. flavus strains are non-aflatoxigenic, they are not necessarily non-pathogenic. In other words, they are able to reduce the level of aflatoxin contamination but might still cause severe crop disease and yield losses.

Apart from non-aflatoxigenic A. flavus strains, antagonistic microbes, including various bacteria [32-40] and yeasts [41-44], have shown remarkable inhibitory effects on the growth and/or on aflatoxin production of aflatoxigenic strains and have been considered as potential candidates for biocontrol of aflatoxin contamination at pre-harvest. Among the antagonists, fungi of the genus Trichoderma are possibly the most diffused biocontrol agents worldwide [45]. Trichoderma are free-living, mostly soil-resident, filamentous fungi that comprise rhizosphere-competent strains associated with root ecosystems [46]. Beneficial effects of Trichoderma include the ability to suppress both soil-borne and foliar plant pathogens, improvement of plant resistance to abiotic stresses and diseases, enhancement of mineral plant nutrition, promotion of plant growth and increase in crop productivity $[47,48]$. The outstanding success of Trichoderma spp. as biocontrol agents arises from their capability to exhibit multiple mechanisms of antagonistic action against plant pathogens [49]. Being fast-growing and metabolically flexible fungi able to use a variety of organic materials as food source, they are excellent competitors in soil environment. In addition, they produce a number of secondary metabolites inhibitory to plant pathogens [50], which function as chemical weapons within the so-called interference competition [51]. Although Trichoderma spp. are historically among the most studied agents for the biocontrol of soil pathogens, so far only few Trichoderma species and strains have been tested for biological control of A. flavus and aflatoxin production [52-54]. In this study we examined the inhibitory action of 20 antagonistic Trichoderma isolates against an aflatoxigenic strain of A. flavus and their effect on aflatoxin production, with an emphasis on the effect of Trichoderma metabolites and their involvement in the mode of action. In this regard, the effect of metabolites produced by two Trichoderma strains (namely T. harzianum T44 and T. polysporum T60) on the regulation of aflatoxin biosynthesis genes was investigated. In particular, we focused on the expression of the two regulatory genes aflR and aflS and four structural genes of the aflatoxin biosynthesis cluster, aflA, aflD, aflO and aflQ, by using the reverse transcriptase quantitative approach. Our results suggest that, unlike other microbial agents [55], Trichoderma are not able to downregulate the toxin biosynthesis, and aflatoxin reduction is based on other mechanisms, such as enzyme degradation or complexation. 


\section{Results}

\subsection{Antagonism of Trichoderma Isolates against A. flavus}

The average daily radial growth of $A$. flavus ITEM 9 (Af-9) was $4.6 \mathrm{~mm} /$ day; this is considerably slower than that of most of the Trichoderma isolates. The daily radial growth of Trichoderma colonies varied from 4.9 to $22.9 \mathrm{~mm}$ / day; that is up to three to four times faster than Af-9 (Figure 1). The fast-growing Trichoderma isolates rapidly spread and surrounded the colony of $A$. flavus, thus stopping its further enlargement. In several confrontations, the early contact between Trichoderma isolates and $A$. flavus resulted in the arrest of $A$. flavus growth before the differences between $R_{A 1}$ and $R_{A 2}$ became apparent (Figures 2 and 3 ). As a result, in these confrontations, the value of percent inhibition of Af- 9 colony growth was not statistically different from the control values (Table 1), in spite of the capability of Trichoderma to stop the growth of Af-9. More insight into the antagonistic potential of the Trichoderma isolates against $A$. flavus was obtained with the study of colony interactions, observed after 21 days of co-culture (Table 1, Figure 3). Overall, only type 1, 3 and 4 colony interactions were observed (Table 1); in none of the interactions have we observed overgrowth of A. flavus on Trichoderma spp. The Trichoderma isolates T32, T50, ITEM 908, T61, T60 and T62 arrested the growth of $A$. flavus after contact and aggressively overgrew the A. flavus colony (interaction type 1). The Trichoderma isolates T58, T38, T48, T8, T36 and T46 showed a different type of aggressive interaction with A. flavus, which resulted in a clear, $\geq 4 \mathrm{~mm}$-wide inhibition zone (type 4 ). The rest of the strains (ITEM 4484, T54, ITEM 908-5, T11, T37, T41, T44, T51) showed a less aggressive interaction (type 3), with a mutual $\leq 2 \mathrm{~mm}$-wide inhibition zone.

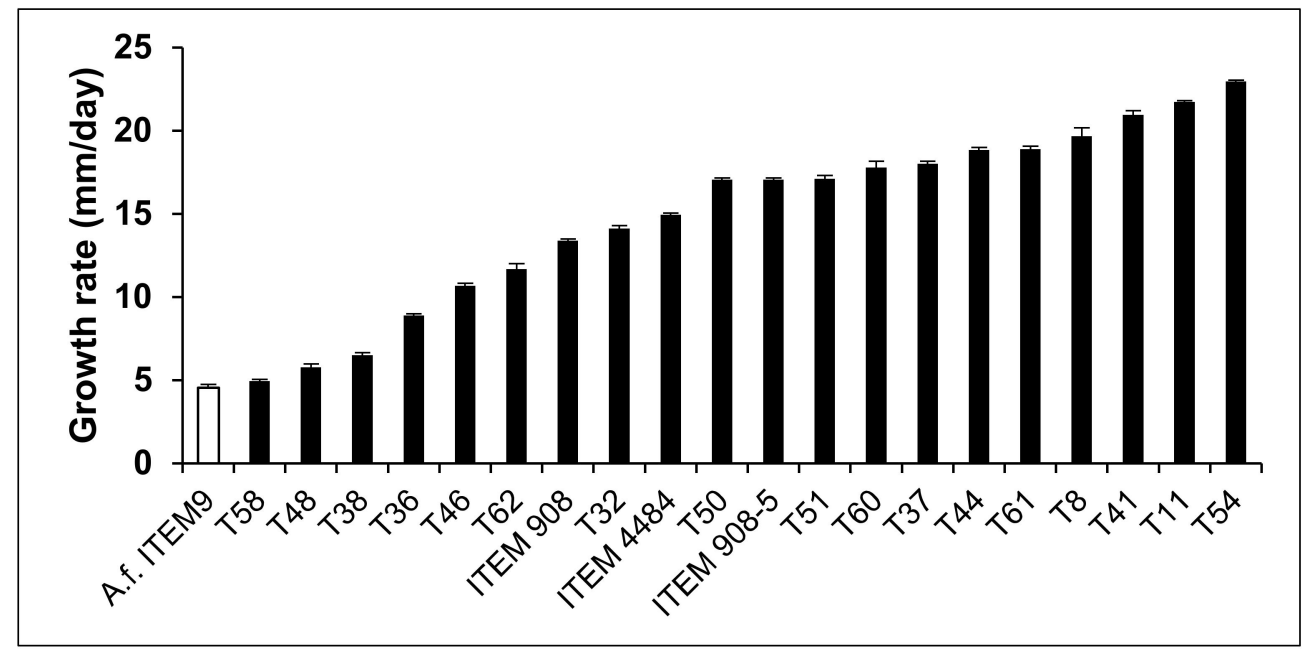

Figure 1. Average radial growth rate (mm/day) of A. flavus Af-9 and different Trichoderma isolates. Radial growth was measured daily in dual cultures for 3 days, until colony contact or until the arrest of growth if contact did not occur. Values are means $\pm \operatorname{SD}(n=3)$. 


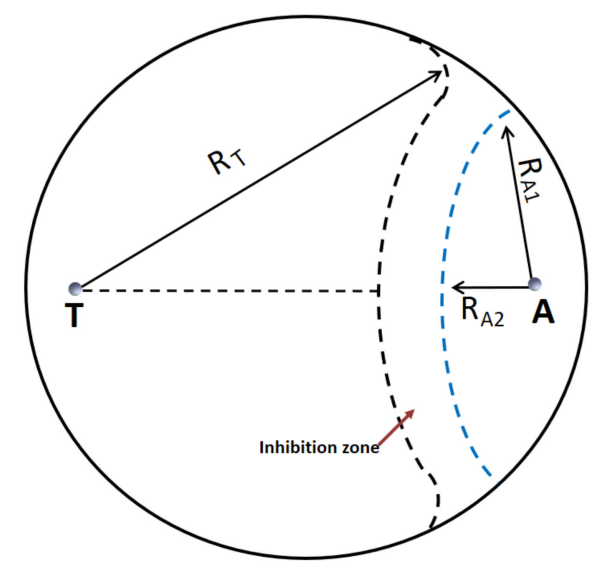

Figure 2. Representation of dual culture tests with Trichoderma spp. and A. flavus Af-9. T and A are the inoculation points of Trichoderma and Af-9, respectively. Undisturbed growth of either Af-9 or Trichoderma was assumed to be $\mathrm{R}_{\mathrm{A} 1}$ and $\mathrm{R}_{\mathrm{T}}$, respectively. The percent inhibition of Af- 9 radial growth was calculated as $\% \mathrm{I}_{\mathrm{DC}}=\left(\mathrm{R}_{\mathrm{A} 1}-\mathrm{R}_{\mathrm{A} 2}\right) / \mathrm{R}_{\mathrm{A} 1} \times 100 \%$.

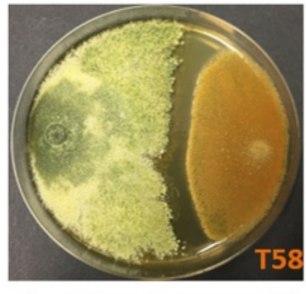

T. asperrellum
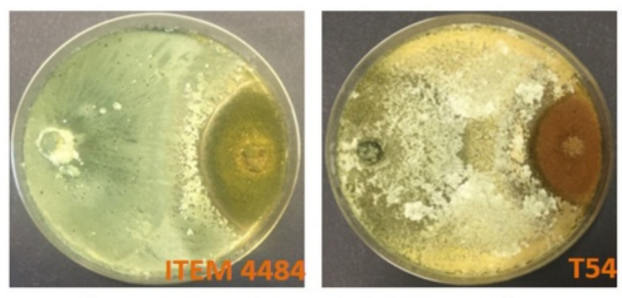

T. citrinoviride
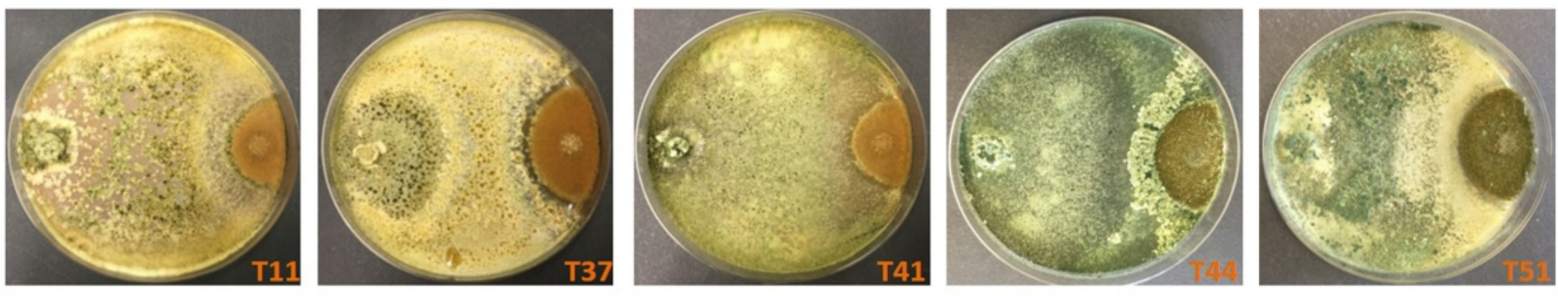

T. harzianum

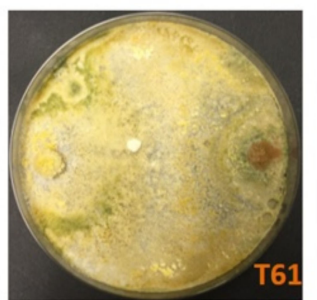

T. harzianum

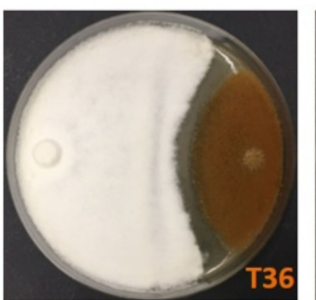

T. inhamatum

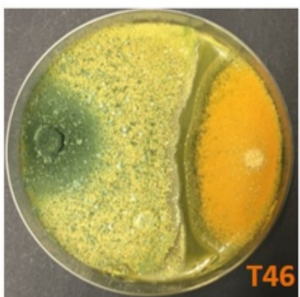

$\overline{\text { T. parceramosus }}$
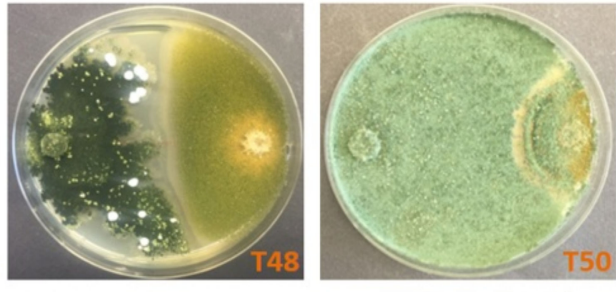

T. atroviride
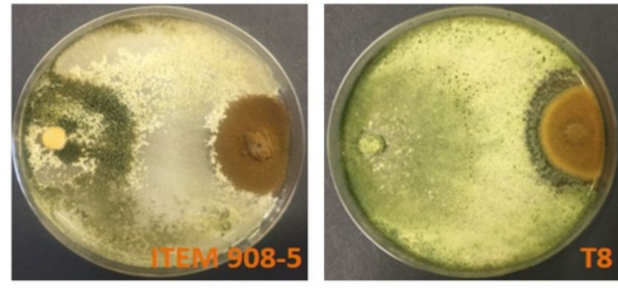

T. harzianum

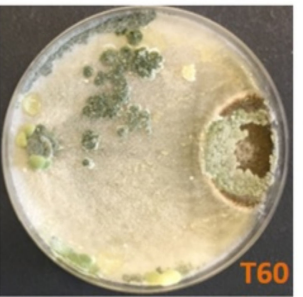

T. polysporum

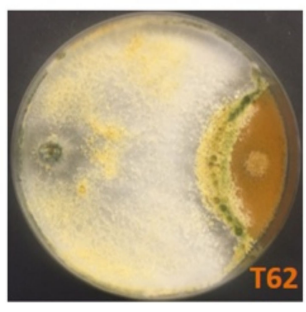

T. viride

Figure 3. Confrontation test of Trichoderma spp. (on the left-hand side of the Petri dishes) and A. flavus Af-9 (on the right-hand side) colonies. Dual cultures on PDA after 21-day growth at $25{ }^{\circ} \mathrm{C}$. 
Table 1. Inhibition of the aflatoxigenic isolate Af-9 growth by Trichoderma spp. and type of colony interactions in confrontation tests (dual cultures) on PDA.

\begin{tabular}{|c|c|c|c|}
\hline $\begin{array}{l}\text { Antagonistic } \\
\text { Species/Strain }\end{array}$ & $\% \mathbf{I}_{\mathrm{DC}}{ }^{(\mathbf{a})}$ & $p$ Value $^{(b)}$ & Interaction Type ${ }^{(c)}$ \\
\hline \multicolumn{4}{|c|}{ Trichodermaasperellum } \\
\hline T58 & $35.6 \pm 3.45$ & $* *$ & 4 \\
\hline \multicolumn{4}{|c|}{ Trichodermaatroviride } \\
\hline T32 & $2.88 \pm 0.98$ & n.s. & 1 \\
\hline T38 & $20.0 \pm 3.18$ & $*$ & 4 \\
\hline T48 & $42.3 \pm 3.21$ & $* *$ & 4 \\
\hline T50 & $0.00 \pm 0.00$ & n.s. & 1 \\
\hline \multicolumn{4}{|c|}{ Trichoderma citrinoviride } \\
\hline ITEM 4484 & $4.45 \pm 1.93$ & n.s. & 3 \\
\hline T54 & $1.90 \pm 1.65$ & n.s. & 3 \\
\hline \multicolumn{4}{|c|}{ Trichoderma harzianum species complex (incl. T. atrobrunneum) } \\
\hline ITEM 908 & $12.5 \pm 2.43$ & $* *$ & 1 \\
\hline ITEM 908-5 & $5.75 \pm 2.00$ & n.s. & 3 \\
\hline T8 & $5.24 \pm 1.75$ & n.s. & 4 \\
\hline T11 & $0.00 \pm 0.00$ & n.s. & 3 \\
\hline T37 & $0.00 \pm 0.00$ & n.s. & 3 \\
\hline $\mathrm{T} 41$ & $0.00 \pm 0.00$ & n.s. & 3 \\
\hline T44 & $0.00 \pm 0.00$ & n.s. & 3 \\
\hline T51 & $5.24 \pm 1.75$ & n.s. & 3 \\
\hline T61 & $1.15 \pm 1.20$ & n.s. & 1 \\
\hline \multicolumn{4}{|c|}{ Trichoderma inhamatum } \\
\hline T36 & $37.9 \pm 0.01$ & $* *$ & 4 \\
\hline \multicolumn{4}{|c|}{ Trichodermaparceramosus } \\
\hline $\mathrm{T} 46$ & $21.2 \pm 0.85$ & $* *$ & 4 \\
\hline \multicolumn{4}{|c|}{ Trichodermapolysporum } \\
\hline T60 & $2.30 \pm 1.99$ & n.s. & 1 \\
\hline \multicolumn{4}{|l|}{ Trichodermaviride } \\
\hline T62 & $3.70 \pm 1.60$ & n.s. & 1 \\
\hline
\end{tabular}

(a) Percent inhibition of radial growth of $A$. flavus colonies; means $\pm \mathrm{SD}(n=3) .{ }^{(\mathrm{b})}$ Asterisks indicate statistically significant differences from control values by one-way ANOVA. ${ }^{* *}=p<0.01 ;{ }^{*}=p<0.05$, n.s. $=$ not significant. (c) Interaction type, modified from Whipps (1987) [52]: 1 = Trichoderma overgrowing A. flavus and A. flavus stopped, $1 / 2=$ Trichoderma overgrowing $A$. flavus but $A$. flavus still growing; $2 / 1=A$. flavus overgrowing Trichoderma but Trichoderma still growing; $2=A$. flavus overgrowing Trichoderma and Trichoderma stopped; $3=$ slight mutual inhibition (inhibition zone $\leq 2 \mathrm{~mm}$-wide); 4 = strong mutual inhibition (inhibition zone $\leq 4 \mathrm{~mm}$-wide).

\subsection{Inhibitory Effect of Trichoderma Metabolites on Growth of A. flavus}

Production of metabolites inhibitory to Af-9 by the 20 Trichoderma spp. isolates was investigated in both the standard Czapek Dox-Agar medium (CDA) and in Czapek Dox-Agar supplemented with $2 \%$ peanut flour (CDP). For all the isolates of Trichoderma tested, the inhibitory effect on growth of $A$. flavus was lower in CDP compared to CDA (Figure 4A,B). On CDA, 16 out of 20 isolates of Trichoderma significantly inhibited Af-9; in percentages, that ranged from $9 \pm 1 \%$ to $100 \pm 0 \%$ (Figure $4 \mathrm{~A}$ ). On CDP, only 8 out of 20 isolates resulted in a significant growth inhibition of Af-9; in percentages, that ranged from $13 \pm 1 \%$ to $65 \pm 3 \%$ (Figure 4B). All of them were also inhibitory on CDA. The most effective strains belonged to the species T. atroviride (T32 and T50), T. citrinoviride (ITEM 4484), T. harzianum species complex (ITEM 908-5, T11, T41, T61) and T. polysporum (T60). The strain T60 was the most effective in both media, resulting in $65 \pm 3 \%$ and $100 \pm 0 \%$ growth inhibition on $\mathrm{CDP}$ and CDA, respectively. 
A

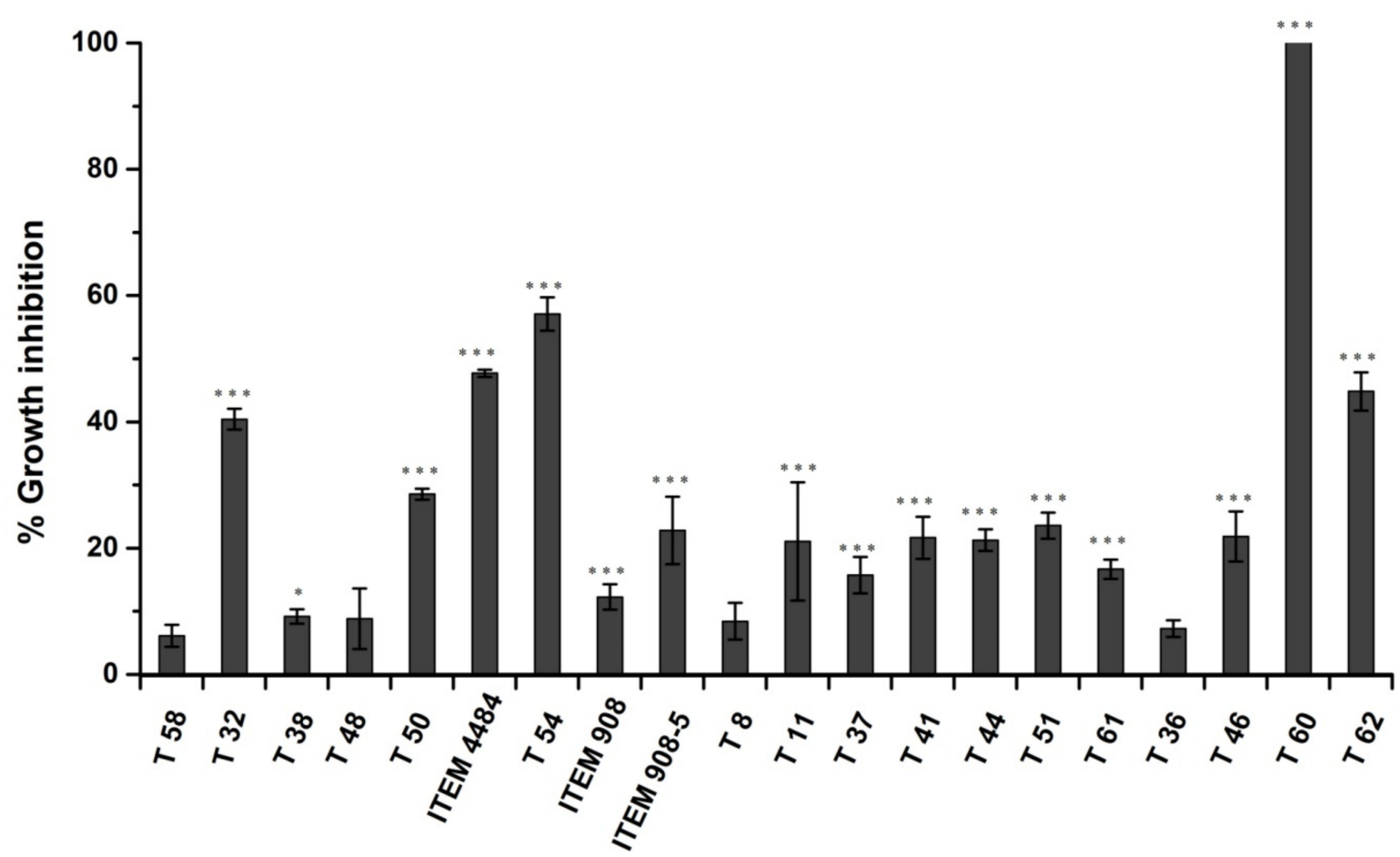

B

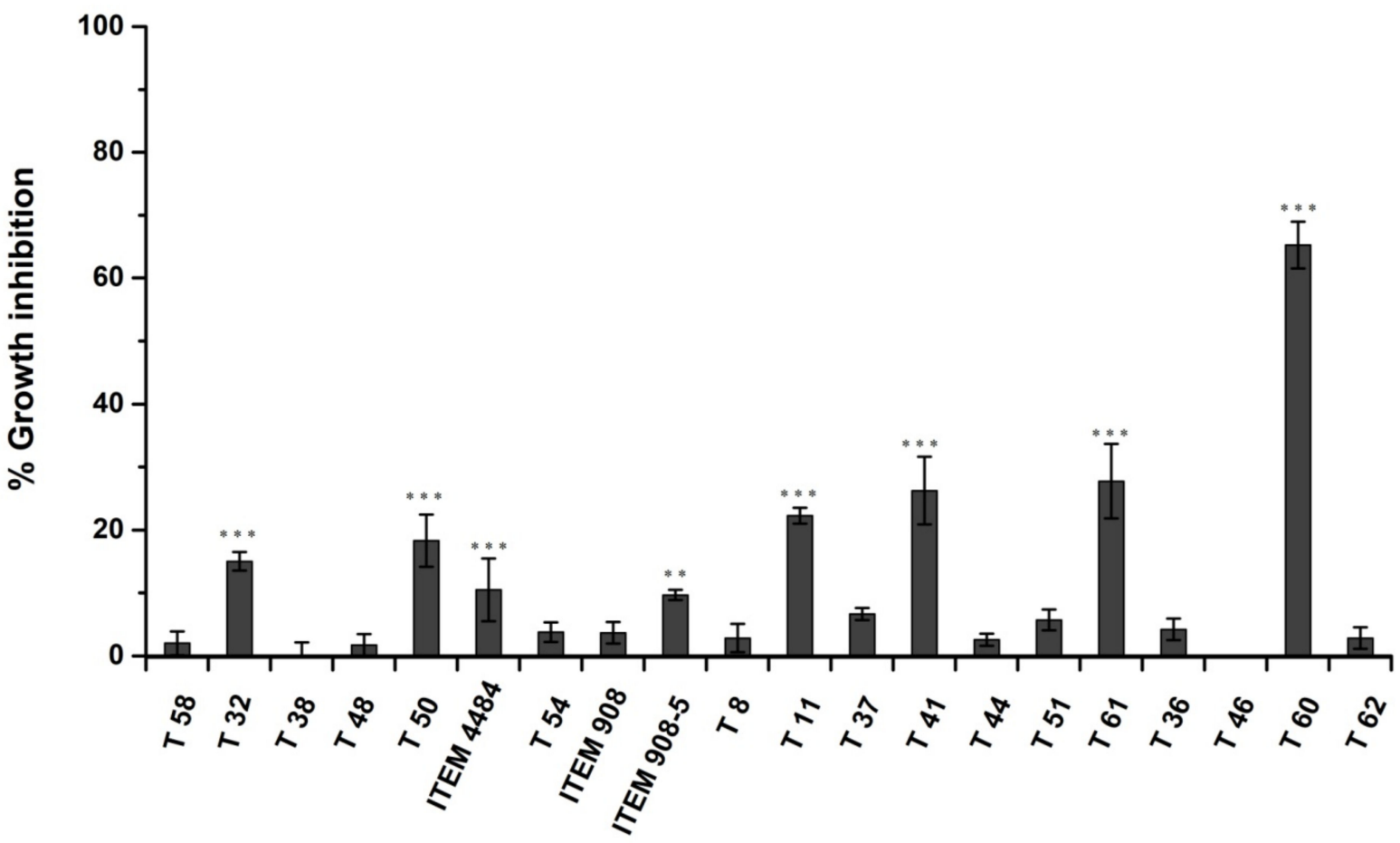

Figure 4. Inhibitory effect of Trichoderma spp. metabolites on the growth of A. flavus Af-9. The isolates of Trichoderma spp. were grown on sterilized cellophane sheets in Petri dishes containing Czapek Dox-Agar (A) or Czapek Dox-Agar supplemented with 2\% peanut flour (B) (see text for more details) for 5 or 3 days, respectively. After removal of the cellophane sheet, the dishes were inoculated with Af- 9 and incubated at $25^{\circ} \mathrm{C}$ with $12 / 12$ photoperiod for 6 days. Values are the means $\pm \operatorname{SD}(n=3)$ of the percent reduction of colony diameter with respect to control. Asterisks indicate statistically significant values at $p<0.05\left(^{*}\right), p<0.01\left(^{* *}\right)$ or $=p<0.001\left({ }^{* * *}\right)$ by one-way ANOVA. 


\subsection{Inhibitory Effect of Trichoderma Metabolites on $A f B_{1}$ Production by A. flavus}

The inhibitory effect of Trichoderma metabolites on $\mathrm{AfB}_{1}$ production by Af-9 was initially investigated using both the media CDA and CDP. Analyses of $\mathrm{AfB}_{1}$ content in the media carried out after 7 and 15 days of growth showed that Af- 9 was not able to produce $\mathrm{AfB}_{1}$ on $\mathrm{CDA}$, regardless of the presence or absence of Trichoderma metabolites (data not shown). On the contrary, $7.3 \pm 1.0$ and $11.2 \pm 2.6 \mu \mathrm{g} / \mathrm{g}$ of $\mathrm{AfB}_{1}$ were detected in control plates of CDP, respectively after 7- and 15-day growth of Af-9. Therefore, only $\mathrm{CDP}$ was used for the assessment of the inhibitory activity of Trichoderma metabolites on $\mathrm{AfB}_{1}$ production.

The inhibitory effect of Trichoderma isolates on $\mathrm{AfB}_{1}$ production is shown in Figure 5. Most Trichoderma isolates (14 out of 20) released metabolites in the medium that reduced significantly $(p<0.001)$ the production of $\mathrm{AfB}_{1}$, both at 7 and 15 days (Figure 5$)$. In two cases (isolates T54 and T51), the inhibitory effect was temporary, since it was observed at 7 days but not at 15 days (Figure 5). Two isolates (T38 and T37) did not inhibit production of $\mathrm{AfB}_{1}$ either at 7 or 15 days (Figure 5). The reduction of $\mathrm{AfB}_{1}$ production by Af- 9 ranged from 5.7 to $84.9 \%$ and from 2.5 to $71.1 \%$, respectively, after 7 and 15 days. Interestingly, the isolates ITEM 4484 and T8 increased the production of $\mathrm{AfB}_{1}$ by Af- 9 , in spite of the former isolate being significantly inhibitory and the latter not being significantly inhibitory to Af-9 growth (Figure 4). The increase in $\mathrm{AfB}_{1}$ production was initially as high as $40 \%$ and then decreased to $30 \%$ at 15 days of growth (Figure 5 ).

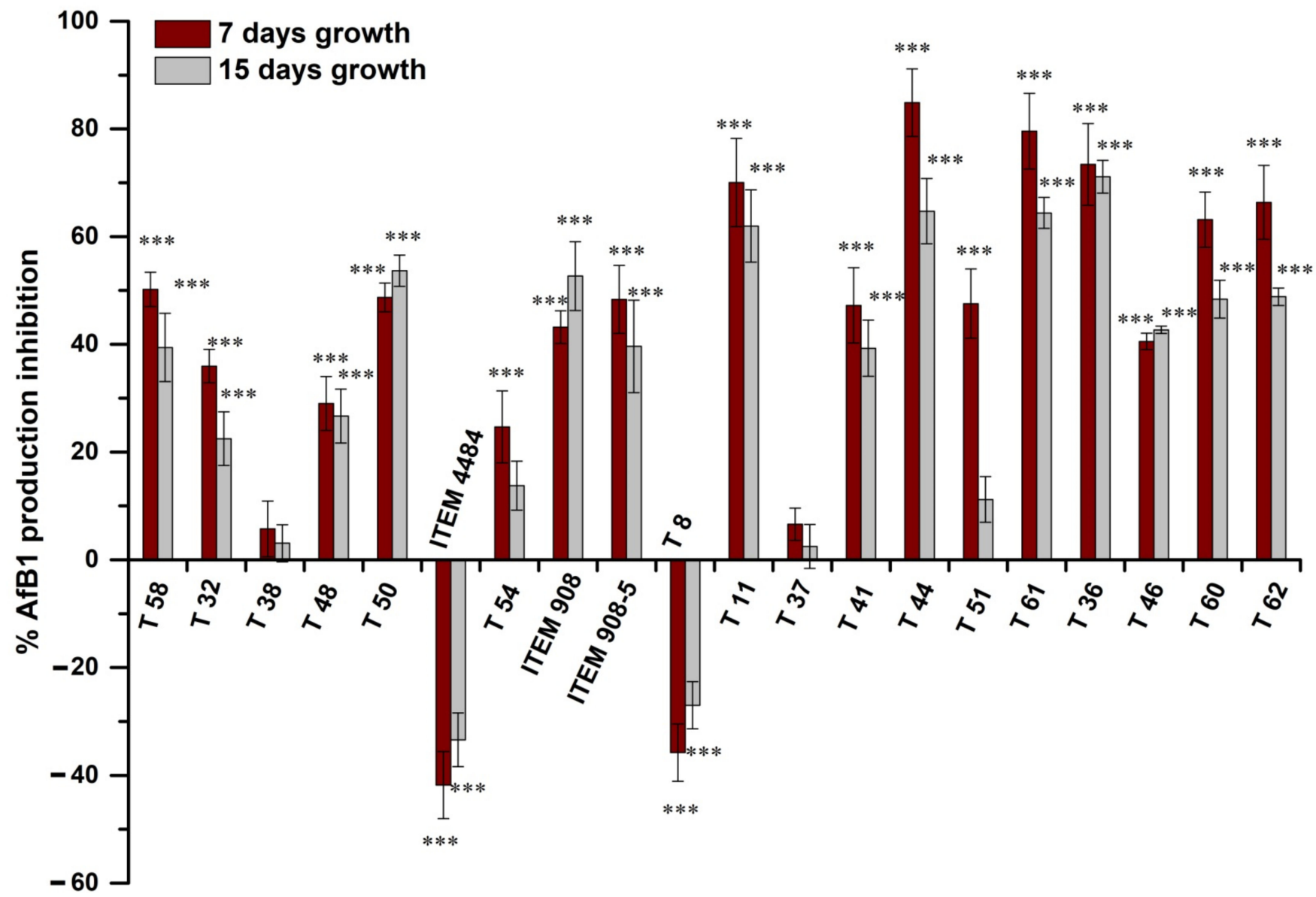

Figure 5. Percent reduction of $\mathrm{AfB}_{1}$ production by Af- 9 grown for 7 and 15 days on $\mathrm{CDP}$ containing Trichoderma metabolites, with respect to control. In control plates, $7.3 \pm 1.0$ and $11.2 \pm 2.6 \mu \mathrm{g} / \mathrm{g}$ of $\mathrm{AfB}_{1}$ were produced after 7 and 15 days, respectively. Values are the means $\pm \mathrm{SD}$ of three replicates; statistically significant differences with control by one-way ANOVA are indicated by asterisks above the bar $\left({ }^{* * *}=p<0.001\right)$. 


\subsection{Analysis of Aflatoxin Biosynthesis Gene Expression in Relation to the Control of Trichoderma}

In order to investigate the molecular mechanism of the inhibitory effect exerted by Trichoderma metabolites on $\mathrm{AfB}_{1}$ production, the expression levels of aflatoxin biosynthesis genes were studied in Af-9 grown on CDP plates that were pre-inoculated with either Trichoderma isolate T60 or isolate T44. These two isolates were presumed to have different modes of inhibition of $\mathrm{AfB}_{1}$ production. Indeed, while T60 metabolites inhibited both mycelial growth and $A_{f B}$ production, $T 44$ was very effective in inhibiting $A_{f} B_{1}$ production but did not significantly inhibit the growth of Af-9 (Figures 4 and 5).

In this regard, the $\mathrm{AfB}_{1}$ production was determined per milligram of mycelium fresh weight so that, through the normalization of $\mathrm{AfB}_{1}$ content per unit of Af- 9 biomass, the effect of reduction of $\mathrm{AfB}_{1}$ due to reduced growth was distinguishable from reduction due to the downregulation of biosynthesis. $\mathrm{AfB}_{1}$ was measured in the mycelium of Af-9 after 2 and 5 days of growth. As shown in Figure 6A, in the presence of T44 metabolites, a significant reduction (90.3\%) of $\mathrm{AfB}_{1}$ production was observed after 5 days of growth. Conversely, when $A$. flavus was grown on plates pre-inoculated with T60, no significant difference was observed in the normalized production of $\mathrm{AfB}_{1}$ either at 2 or 5 days after inoculation (d.a.i.). The expression levels of the two regulatory genes (aflR and aflS) and four structural genes ( $\mathrm{a} f \mathrm{~A}$, aflD, aflO and $a f l Q$ ) of the aflatoxin biosynthesis cluster were analyzed in Af- 9 after 2 days of growth in control conditions or in plates pre-inoculated with the strain T44 or the strain T60. In Af-9 grown on CDP that was pre-inoculated with the isolate T44, the two regulatory genes aflR and aflS had a similar transcriptional trend, with a higher expression level than in control; on the contrary, no difference from control was observed when strain T60 was used (Figure 6B). A different transcriptional profile was observed among the structural genes (Figure 6B). In particular, for both the Trichoderma strains the expression levels of aflA and aflD showed no significant variation between control and treatment. On the other hand, the expression level of aflO decreased when Af-9 grew on medium pre-inoculated with either Trichoderma strains, more markedly with strain T44. By contrast, the expression level of aflQ increased significantly, as did that of the regulatory genes aflR and aflS when strain T44 was used in the pretreatment of the growth medium.

A

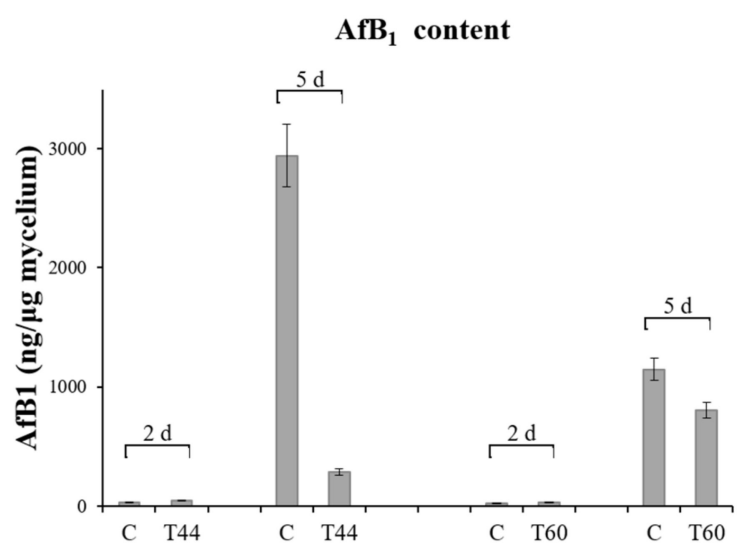

B
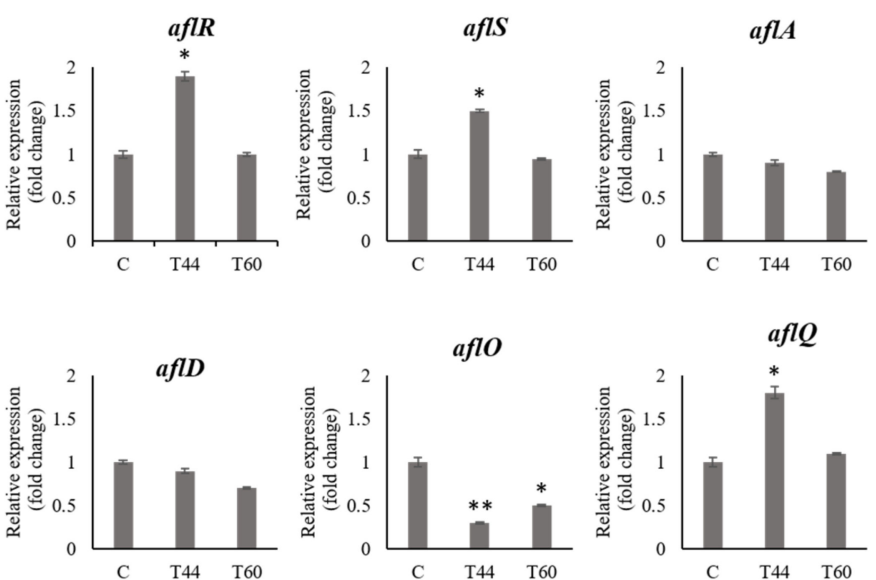

Figure 6. (A) Aflatoxin $B_{1}$ content in A. flavus Af-9 mycelium after 2 and 5 days of growth on medium untreated (control, c) and pre-inoculated with Trichoderma strains T44 or T60; (B) expression analyses of aflatoxin biosynthesis genes in Af- 9 after 2 days of growth on medium untreated (control, c) and pre-inoculated with Trichoderma strains T44 and T60. The $\beta$-tubulin gene was used as reference gene. Significantly differential gene expression is indicated $\left({ }^{*} p\right.$-value $\leq 0.05 ;{ }^{* *} p$-value $\left.\leq 0.01\right)$. 


\section{Discussion}

Contamination of commodities with aflatoxins is a major issue for food safety and trade worldwide. Control of contamination at multiple points of the food chain, cultivation, transit, storage and processing, is necessary, but the control of infections by aflatoxigenic fungi at pre-harvest appears especially critical [11]. Spreading non-toxigenic A. flavus strains that competitively exclude aflatoxigenic strains in the field was first introduced by Cotty and Bayman [56], and this approach has proved to be successful in many cases, leading up to $80 \%$ reduction of aflatoxin contamination. It is currently utilized in cottonand maize-growing areas of the USA and in Kenya and has led to the development of commercial biopesticides AF36 (non-aflatoxigenic strain NRRL 18543) and Afla-Guard ${ }^{\circledR}$ (non-aflatoxigenic strain NRRL 21882) that are marketed in the USA for biocontrol of aflatoxins in groundnut and maize, respectively. However, some drawbacks of the method have been pointed out $[26,27]$, which prompt the search for additional low-environmentalimpact methods of control of aflatoxigenic fungi and aflatoxin in the field. Trichoderma spp. are well known and widely used biocontrol agents of root and foliar plant pathogens. Apart from the direct action against the pathogens, these beneficial fungi are also able to enhance plant mineral nutrition [47] and activate plant defenses and resistance against abiotic and biotic stresses [57,58], including drought [59] and herbivore insects [60,61]. Lately, a few research works reported on the capability of Trichoderma spp. to control A. flavus in the field, both in maize and peanut [62-64]. In the present research work, we have investigated the potential of 20 Trichoderma isolates belonging to different species for biological control of $A$. flavus and aflatoxins, with a focus on the effect of metabolites on A. flavus growth, $\mathrm{AfB}_{1}$ production and expression of genes of aflatoxin biosynthesis.

The confrontation test, also known as dual culture, is a method widely utilized for the in vitro selection of effective biocontrol strains of Trichoderma against various pathogens and has also been utilized for picking isolates antagonistic to A. flavus [65-67]. Usually, in this bioassay, the antagonistic capability of the biocontrol agent against a given pathogen is assessed by determination of the percent inhibition of colony radial growth of the challenged pathogen (\%I). In our trials, we have observed that this parameter is not per se enough for a correct evaluation of the potential antagonistic capability of Trichoderma isolates against Af-9. Indeed, some aggressive and fast-growing Trichoderma isolates did not score high \%I values, since the early contact between Trichoderma and Af-9 resulted in the arrest of pathogen growth before significant differences between the challenged colony growth and the unchallenged colony growth of Af-9 appeared. Therefore, it is very important that the \%I value is carefully considered along with the type of colony interaction that occurs after the contact between the colonies, particularly the capability of the Trichoderma isolate to aggressively overgrow A. flavus (type 1 interaction).

Our experiments showed that in the antagonism of Trichodema spp. against Af-9, an important role is played by the production of metabolites. Metabolites produced by Trichoderma isolates and released in the growth medium were able to inhibit both the colony growth of Af- 9 and its $\mathrm{AfB}_{1}$ production. However, it should be stressed that the effect of metabolites in inhibiting Af-9 growth was strongly affected by the medium used for the assessment. For all the isolates of Trichoderma tested, the inhibitory effect on A. flavus growth was higher in CDA compared to the same medium supplemented with $2 \%$ peanut flour (CDP). It is conceivable that some components of peanut flour either reduce the production of inhibitory metabolites by Trichoderma or enhance the A. flavus resistance. From a practical standpoint, this highlights the necessity to use media that contain natural components of the host plant for testing antagonistic efficacy of Trichoderma biocontrol isolates. Likewise, the presence of peanut flour in the medium enhanced the mycotoxigenicity of Af- 9 and $\mathrm{AfB}_{1}$ biosynthesis, consistently with what had been observed in previous studies with other plant components $[68,69]$. It should also be noted that, for this experiment, "true" control plates were difficult to design. The pre-growth of Trichoderma on the medium that was subsequently exploited by Af-9 resulted in partial depletion of nutrients, which may have affected both Af-9 growth and $\mathrm{AfB}_{1}$ production. Conversely, depletion did not 
occur in control plates. Nevertheless, the experiment allowed us to assess the biocontrol capability of the different Trichoderma isolates comparatively. The inhibition of $A$. flavus colony growth by metabolites of Trichoderma was not necessarily associated with inhibition of $\mathrm{AfB}_{1}$ production and vice versa. Metabolites of the isolates T44 and T60 that were released in CDP proved to have a strong inhibitory effect on $\mathrm{AfB}_{1}$ production (approx. by $65-85 \%$ for T44 and 48-63\% for T60, Figure 5). However, these two strains had a different effect on A. flavus growth (Figure 4). While T44 did not significantly inhibit mycelial growth, T60 had the highest inhibitory effect among all the strains tested (approx. by 65\% on CDP). A similar differential effect on fungal growth and aflatoxin biosynthesis has been previously reported for some plant metabolites as well [70]. On this premise, it seemed interesting to investigate which inhibitory mechanism led to the reduction of $\mathrm{AfB}_{1}$ content, given the fact that only in the case of T60, but not in that of T44, could the lower amount of the mycotoxin be due to the reduction of Af- 9 growth. Hence, the effect of metabolites of T44 and T60 on production of $\mathrm{AfB}_{1}$ was studied in correlation with the expression of some genes of aflatoxin biosynthesis cluster, in order to investigate the possible interference of Trichoderma metabolites at some points of the aflatoxin biosynthesis pathway. When the $\mathrm{AfB}_{1}$ content was analyzed in the 5-day-old mycelium of Af-9, the results confirmed that the reduction caused by metabolites of T60 was due to the inhibition of growth, while for metabolites T44, a different mechanism was conceivable. Recent studies have reported that the use of biocontrol agents or natural products can inhibit the production of $\mathrm{AfB}_{1}$ by downregulation of the genes involved in the biosynthesis of $\mathrm{AfB}_{1}$, even though the molecular mechanism behind this inhibition activity has not yet been completely determined [71]. For our study, we selected the two aflatoxin biosynthesis regulatory genes aflR and aflS, and the four structural genes, aflA, aflD, aflO and aflQ, for analysis of gene expression in 2-day-old mycelium of Af-9, since the regulation and expression of biosynthetic genes usually precede the production and accumulation of aflatoxin in the mycelium [72]. The aflR and aflS genes encode cluster-specific transcriptional factors that were suggested to interact to modulate and coordinate the expression of aflatoxin structural genes [73,74]. Among the selected structural genes, aflA and aflD act at the early phase of the biosynthesis pathway. The aflA gene encodes one of the two fatty acid synthases responsible for the first polyketide structure of the aflatoxin molecule, and the aflD gene encodes the enzyme responsible for the formation of the intermediate averantin. The other two genes aflO and aflQ are involved in the production of sterigmatocystin and hydroxyl-methylsterigmatocystin, the precursor of $\mathrm{AfB}_{1}$, respectively, acting in the later stages of the biosynthesis pathway [71]. From the analysis of expression levels in A. flavus grown in the presence of T60 metabolites, no difference was found compared to control. These findings were consistent with the results of $\mathrm{AfB}_{1}$ content, confirming that the T60 metabolites did not affect the biosynthetic mechanism of the mycotoxin. In the case of T44 metabolites, which led to a reduction in $\mathrm{AfB}_{1}$ production, the expression levels of most biosynthetic genes did not appear to be directly related to inhibitory activity. In fact, both the regulatory genes aflR and aflS and the structural gene aflQ showed an upregulation compared to the control. Conversely, the transcriptional levels of aflA and aflD genes remained unchanged, while only the aflO gene seemed downregulated compared to the control and apparently in line with the reduction in $\mathrm{AfB}_{1}$ production. Usually, the inhibitory activity exerted by biological control agents on the $\mathrm{AfB}_{1}$ biosynthesis by $A$. flavus is correlated with the downregulation of all or most of the approximately 27 genes composing the aflatoxin biosynthesis cluster $[55,75]$. In our study, we observed an increase in the expression of aflR and aflS in the presence of T44 metabolites, and only the aflO was downregulated. Further analyses are necessary to examine whether the expression of other genes of the biosynthesis cluster may be affected and establish whether the negative regulation of $\mathrm{AfB}_{1}$ production occurs at the biosynthesis cluster level or during translational and/or post-translational stages, causing low levels of proteins or lack of functionality. It cannot be excluded that some of the metabolites produced by strain T44 could activate a signaling pathway, leading to the upregulation of regulatory genes $a f l R$ and aflS of the aflatoxin cluster. On the other hand, the observed reduction 
in aflatoxin accumulation in the culture media could be due to mechanisms triggered by other Trichoderma metabolites. Several works have reported the ability of microorganisms, including Trichoderma species, to produce enzymes capable of degrading or modifying mycotoxin molecules [76]. Finally, it should be considered that in confrontation tests, 2 out of the 20 Trichoderma strains tested, namely ITEM 4484 and T8, resulted in an augmented capability of Af-9 to produce $\mathrm{AfB}_{1}$ (Figure 5), even if the antagonists significantly reduced Af-9 growth. While upregulation of $\mathrm{AfB}_{1}$ biosynthesis genes cannot be ruled out, other hypotheses, including digestion of medium components by Trichoderma enzymes, which generate compounds boosting $\mathrm{AfB}_{1}$ production, also deserve further investigation.

The option of using Trichoderma spp. for biocontrol of aflatoxigenic fungi may offer a few advantages in respect to the use of non-aflatoxigenic A. flavus strains. First, the non-aflatoxigenic $A$. flavus strains are not necessarily non-pathogenic, and they might still cause disease and yield loss. As broad-spectrum biocontrol agents, Trichoderma may also protect the plants from the attack of other plant pathogens in addition to A. flavus $[58,77,78]$. Finally, the indirect action of Trichoderma on the enhancement of plant resilience to drought stress and on the prevention of insect pest damages, both of which are factors facilitating aflatoxin occurrence [79], is one more point for consideration of Trichoderma in the context of $A$. flavus control and prevention of aflatoxin occurrence.

\section{Conclusions}

In conclusion, the results reported herein have shown the potential of isolates belonging to different species of Trichoderma to be biocontrol agents for A. flavus and prevent aflatoxin accumulation. Both of these properties may be heavily influenced by the presence of host-plant-derived components in the growth medium; therefore, the in vitro selection of effective strains for further assessment should be compiled, taking into account the crop on which they will be used. The biocontrol Trichoderma strains may arrest fungal growth, reduce aflatoxin production or both. Metabolites of Trichoderma spp. play a role in their mechanism of action, although with a diversity of modes. Some are inhibitory to $A$. flavus growth; others reduce the accumulation of aflatoxin, presumably via degradation. Thus, an effective biocontrol strategy may be based on the combined use of multiple isolates with different mechanisms of action. Although further studies are envisaged to identify the metabolites involved in the biocontrol of A. flavus and prevention of aflatoxin accumulation, as well as for assessment of the efficacy under controlled and field conditions, Trichoderma spp., including a few strains tested within the present work, qualify as promising agents and possible alternative options to other biocontrol agents already in use.

\section{Materials and Methods}

\subsection{Fungal Strains}

The isolates of Trichoderma spp. used in this study were collected from soil or plant debris, or obtained from the culture collection of the Institute of Science of Food Production (ITEM Collection, http: / / www.ispa.cnr.it/Collection/ (accessed on 2 December 2021), Bari, Italy) (Table 2). All the isolates were identified morphologically, according to Gams and Bisset [80]. The commercial biocontrol strain T. atrobrunneum ITEM 908 (T. harzianum species complex, formerly T. harzianum ITEM 908) was previously molecularly characterized [81] by analysis of the sequences of the internal transcribed spacer regions ITS- 1 and ITS-2 of the nuclear rDNA and of a fragment of the translation elongation factor gene TEF- $1 \alpha$, according to Chaverri et.al. [82]. The mutant strain ITEM 908-5 was generated by UV irradiation of the parental strain ITEM 908 [83]. The $\mathrm{AfB}_{1}$-producing strain Aspergillus flavus ITEM 9 (Af-9 = NRRL 3251, ATCC 36061) was used for all the tests throughout the work. Af-9 was originally isolated from walnuts in the USA and is a high AfB $_{1}$-producing strain [84]. Fungal cultures were maintained in purity on potato dextrose agar (PDA, Oxoid, Italy) slants at $+5^{\circ} \mathrm{C}$, which were used for preparation of fresh cultures and inocula. 
Table 2. Strains of Trichoderma spp. used in this study.

\begin{tabular}{lll}
\hline Species/Strain ${ }^{(a)}$ & Geographical Origin & Source \\
\hline Trichoderma asperrellum & & \\
T58 & Not known & Not known \\
Trichoderma atroviride & Not known & \\
T32 & Not known & Not known \\
T38 & Italy & Not known \\
T48 & USA & Soil \\
T50 & & Corn kernel \\
Trichoderma citrinoviride & Austria & \\
ITEM 4484 & Not known & Forest soil \\
T54 & Italy & Maize \\
Trichoderma harzianum species complex (incl. T. atrobrunneum) & \\
ITEM 908 ${ }^{(b)}$ & - & Olive \\
ITEM 908-5 & Italy & UV-mutant of ITEM 908 \\
T8 & Italy & Mushroom substrate \\
T11 & Italy & Corn kernel \\
T37 & Borneo, Asia & Seedling soil mix \\
T41 & Italy & Soil \\
T44 & USA & Mushroom substrate \\
T51 & Not known & Corn kernel \\
T61 & & Not known \\
Trichoderma inhamatum & Not known & \\
T36 & & Not known \\
Trichoderma parceramosus & Italy & \\
T46 & & Mushroom substrate \\
Trichoderma polysporum & Italy & \\
T60 & & Chestnut soil \\
Trichoderma viride & Eggplant leaf \\
T62 & Italy & \\
\hline a) & & \\
\hline
\end{tabular}

(a) Morphological species determined according to Gams and Bisset [80]. The strains with an ITEM number are from the culture collection of the Institute of Sciences of Food Production (http:/ / www.ispa.cnr.it/Collection/ (accessed on 2 December 2021)). ${ }^{(b)}$ Identified as T. atrobrunneum by sequence analysis of ITS-1, ITS-2 and TEF- $1 \alpha$, as reported by Fanelli et al., 2018 [81].

\subsection{Antagonism of Trichoderma spp. against A. flavus}

The antagonism and colony interaction between each Trichoderma spp. isolate and Af-9 were studied in vitro by dual cultures. Petri dishes of $9 \mathrm{~cm}$ in diameter containing $20 \mathrm{~mL}$ of PDA were inoculated $1 \mathrm{~cm}$ apart from the edge of the plate with a $6 \mathrm{~mm}$-diameter mycelial plug from a fresh culture of Trichoderma and on the opposite side, at a $7 \mathrm{~cm}$ distance from the Trichoderma inoculation point, with a $10 \mu \mathrm{L}$ drop of spore suspension of Af-9 containing $1 \times 10^{7}$ conidia $/ \mathrm{mL}$ in sterile distilled water. All the pathogen-antagonist co-cultures were incubated at $25^{\circ} \mathrm{C} \pm 1$ with $12 / 12$ photoperiod. The radial growth of both the colonies was measured daily until contact or until the arrest of colony growth if contact did not occur because of mutual inhibition, and the average daily radial growth $(\mathrm{mm} /$ day) of each fungus was calculated. The percent inhibition of Af-9 radial growth in dual cultures $\left(\% \mathrm{I}_{\mathrm{DC}}\right)$ was calculated as

$$
\% \mathrm{I}_{\mathrm{DC}}=\left(\mathrm{R}_{\mathrm{A} 1}-\mathrm{R}_{\mathrm{A} 2}\right) / \mathrm{R}_{\mathrm{A} 1} \times 100
$$

where $R_{A 1}$ was the longest radius of the Af- 9 colony, and $R_{A 2}$ was the radius of the Af-9 colony along the line that connected the Af-9 and the Trichoderma inoculation points (Figure 2), measured on the day of contact or the last day of incremental growth, if contact did not occur.

At 21 days after inoculation (d.a.i.), the colony interactions were assessed visually and classified in accordance with Whipps [52] as: $1=$ Trichoderma overgrowing Af-9 and Af-9 stopped; $1 / 2=$ Trichoderma overgrowing Af-9 but Af-9 still growing; $2 / 1=$ Af-9 overgrowing Trichoderma but Trichoderma still growing; 2 = Af-9 overgrowing Trichoderma and Trichoderma stopped; 3 = slight mutual inhibition (inhibition zone $\leq 2 \mathrm{~mm}$-wide); 
4 = strong mutual inhibition (inhibition zone $\leq 4 \mathrm{~mm}$-wide). The experiment was carried out in triplicate.

\subsection{Effect of Non-Volatile Metabolites of Trichoderma spp. on A. flavus Growth}

The inhibitory effect of Trichoderma metabolites on the growth of A. flavus was studied in Czapek Dox-Agar (CDA, Biolife Italiana, Monza, Italy) and Czapek Dox-Agar supplemented with $2 \%(\mathrm{w} / \mathrm{v})$ peanut flour $(\mathrm{CDP})$. For preparation of CDP, peanuts were finely ground in a laboratory mill (Mulino Cyclone, International PBI, Milano, Italy) to particles of $<0.2 \mathrm{~mm} ; 0.4 \mathrm{~g}$ of ground peanuts were transferred into $2.5 \mathrm{~cm}$-diameter and $15 \mathrm{~cm}$ long test tubes that were filled with $20 \mathrm{~mL}$ of melted CDA and autoclaved at $121^{\circ} \mathrm{C}$ for $15 \mathrm{~min}$. After cooling at $55^{\circ} \mathrm{C}$, the medium was thoroughly mixed by a vortex mixer and quickly poured into $9 \mathrm{~cm}$-diameter Petri dishes. After solidification of the medium, a pre-autoclaved $\left(121^{\circ} \mathrm{C}, 15 \mathrm{~min}\right)$ cellophane disc was laid on the medium to cover the entire surface. Mycelial plugs of $6 \mathrm{~mm}$ in diameter were removed from the edge of 5-day-old cultures of Trichoderma and transferred to the center of the Petri dishes, onto the cellophane disc. The cellophane membrane was used to keep the mycelium from invading the medium, at the same allowing time the metabolites to diffuse into the substrate through the cellophane pores. The colonies of Trichoderma were grown for 5 days on CDA and for 3 days on $\mathrm{CDP}$, at $25 \pm 1{ }^{\circ} \mathrm{C}$ with $12 / 12$ photoperiod; then, the cellophane sheets with the overlying Trichoderma colonies were removed. The plates were center-inoculated with a $10 \mu \mathrm{L}$ drop of a $1 \times 10^{7}$ conidia/mL spore suspension of Af- 9 and incubated at $25 \pm 1{ }^{\circ} \mathrm{C}$ with 12/12 photoperiod for 6 days. Control plates were prepared by inoculating Af- 9 on CDA and CDP without previous cultivation of Trichoderma. The experiment was carried out in triplicate. The growth of $A$. flavus was assessed by the colony diameter, measured with a ruler under a dissecting microscope every $24 \mathrm{~h}$. The percent inhibition of the diametral growth of Af- 9 colonies $\left(\% \mathrm{I}_{\mathrm{D}}\right)$ caused by Trichoderma metabolites was calculated with the following formula

$$
\% \mathrm{I}_{\mathrm{D}}=\left(\mathrm{D}_{\mathrm{C}}-\mathrm{D}_{\mathrm{T}}\right) / \mathrm{D}_{\mathrm{C}} \times 100
$$

where $\mathrm{D}_{\mathrm{T}}$ was the average diameter of Af- 9 colonies grown on media pre-inoculated with Trichoderma, and $\mathrm{D}_{\mathrm{C}}$ was the average diameter of Af- 9 colonies grown in control plates.

\subsection{Determination of $A f B_{1}$ by UPLC}

$\mathrm{AfB}_{1}$ was determined by Ultra Performance Liquid Chromatography (UPLC) using the Acquity UPLC system (Waters, Milford, MA, USA). Data acquisition and instrument control were performed by Empower 2 software (Waters). The column used was a $100 \mathrm{~mm} \times 2.1 \mathrm{~mm}$ i.d., $1.7 \mu \mathrm{m}$, Acquity UPLC1 BEH RP-18, with an Acquity UPLC column in-line filter $(0.2 \mu \mathrm{m})$, detected by fluorometric detector without post-column derivatization. The fluorometric detector was set at wavelengths of $365 \mathrm{~nm}$ (excitation) and $435 \mathrm{~nm}$ (emission). The mobile phase was a mixture of water-acetonitrile-methanol $(64: 18: 18, v / v / v)$ at a flow rate of $0.4 \mathrm{~mL} / \mathrm{min}$. The temperature of the column was maintained at $40{ }^{\circ} \mathrm{C}$. In these experimental conditions, the retention time of the $\mathrm{AfB}_{1}$ standard was $3.7 \mathrm{~min}$ (see Supplementary Figure $\mathrm{S1}$ ). $\mathrm{AfB}_{1}$ was quantified by measuring the peak areas of the samples at the retention time of the aflatoxin standard and comparing these areas with the calibration curve of $\mathrm{AfB}_{1}$ in the range of 0.2 to $10.0 \mathrm{ng} / \mathrm{mL}$. The limit of quantification (LOQ) of the method was $0.2 \mathrm{ng} / \mathrm{mL}$ for $\mathrm{AfB}_{1}$, based on a signal to noise ratio of 10:1.

\subsection{Effect of Trichoderma Metabolites on Aflatoxin Production by A. flavus}

Media, inoculations and controls were made in the same way as described for the experiment on the effect of Trichoderma non-volatile metabolites on the growth of Af-9. Each Trichoderma isolate was tested in three replicates. After 7- and 15-day growth of A. flavus, the cultures were sampled for the determination of $\mathrm{AfB}_{1}$. An $8 \mathrm{~mm}$-diameter cork-borer was used to excise mycelial discs at regular distances along the radius of the colony, starting from the inoculation point to the edge of the colony. Excised discs were then transferred to test tubes. The samples (approximately $1 \mathrm{~g}$ ) were precisely weighted and extracted with 
$5 \mathrm{~mL}$ of a methanol-water (80: 20, $v / v$ ) solution in a KS 4000i orbital shaker (IKA Werke $\mathrm{GmbH} \& \mathrm{Co}$. KG., Staufen, Germany) at $250 \mathrm{rpm}$ for $60 \mathrm{~min}$ at room temperature. Samples were then centrifuged, filtered and diluted to obtain extracts, which were stored at $-20{ }^{\circ} \mathrm{C}$ until $\mathrm{AfB}_{1}$ analysis, according to previously described methods $[85,86]$. The inhibition rate of $\mathrm{AfB}_{1}$ production $\left(\% \mathrm{I}_{\mathrm{AfB} 1}\right)$ was calculated with the following formula

$$
\% \mathrm{I}_{\mathrm{AfB} 1}=\left(\mathrm{AfB}_{1 \mathrm{C}}-\mathrm{AfB}_{1 \mathrm{~T}}\right) / \mathrm{AfB}_{1 \mathrm{C}} \times 100
$$

where $\mathrm{AfB}_{1 \mathrm{~T}}$ was the amount of $\mathrm{AfB}_{1}$ produced by $A$. flavus on medium pre-inoculated with Trichoderma, and $\mathrm{AfB}_{1 \mathrm{C}}$ was the amount of $\mathrm{AfB}_{1}$ in the control plates.

\subsection{Effect of Metabolites of Trichoderma on the Expression of Aflatoxin Biosynthesis Genes 5.6.1. Strains Culture and Sampling of Mycelia}

For this study, the Trichoderma strains T44 and T60 and Af-9 were grown on CDP. Preparation of CDP and cultivation of the fungi on cellophane sheets were conducted as described in Section 5.3. After 3 days of growth, the membrane and the colony of Trichoderma were removed from the Petri dish. Then, the medium was inoculated with $100 \mu \mathrm{L}$ of a spore suspension of Af- 9 containing $1 \times 10^{7}$ spores $/ \mathrm{mL}$, which were spread evenly with an L-shaped spreader. As controls, Af-9 was inoculated on cellophane sheets laid on CDP not pre-inoculated with Trichoderma. Cultures of $A$. flavus were incubated at $25 \pm 1{ }^{\circ} \mathrm{C}$ with $12 / 12$ photoperiod, and the mycelium was collected by scraping it off the cellophane at two time points, i.e., 2 and 5 d.a.i. The mycelium samples were stored at $-20{ }^{\circ} \mathrm{C}$ until extraction and $\mathrm{AfB}_{1}$ analysis, according to the procedure described in Section 5.4. For the 2 d.a.i. samples, the cellophane sheets were cut in half, and the mycelium grown in each half was scraped off, weighted, immediately frozen in liquid nitrogen and stored at $-80{ }^{\circ} \mathrm{C}$. The mycelium from one half plate was used for RNA extraction, while the mycelium from the other half plate was used for $\mathrm{AfB}_{1}$ analysis. At each time point, analyses were performed using the pooled mycelium from 10 plates.

\subsubsection{RNA Extraction and cDNA Synthesis}

Total RNA was extracted using the RNeasy kit (Qiagen, Valencia, CA, USA), and an on-column DNase I treatment was performed, according to the manufacturer's protocols. The $A_{260} / A_{280}$ ratio was determined using a NanoDrop 1000 (Thermo Fisher Scientific, Waltham, MA, USA), and gel electrophoresis was performed for qualitative analysis of total RNA. The cDNA was synthesized using $2.0 \mu \mathrm{g}$ total RNA, oligo (dT) 18 primer and random hexamers, and SuperScript III Reverse Transcriptase (Invitrogen, San Diego, CA, USA), according to instructions of the manufacturer.

5.6.3. Expression Analysis of Aflatoxin Biosynthesis Gene by Quantitative Reverse Transcriptase PCR (RT-qPCR)

The StepOne ${ }^{\mathrm{TM}}$ Real-Time PCR System (Applied Biosystem, Waltham, MA, USA) was used to carry out RT-qPCR assays. The transcription profiles of 6 genes of the aflatoxin biosynthesis cluster (aflR, aflS, aflA, aflD, aflO, aflQ) were analyzed, and the housekeeping $\beta$-tubulin gene was used as reference gene. Sequences of primers listed in Table 3 were retrieved from previous publications [55,72]. The sequences of all genes were obtained from the A. flavus NRRL3557 genome database at NCBI (BioProject PRJNA575750). Each reaction was performed in a total volume of $20 \mu \mathrm{L}$ containing cDNA $(3.8 \mathrm{ng} / \mu \mathrm{L}), 12.5 \mu \mathrm{L}$ of SYBR Green Supermix (Bio-Rad, Hercules, CA, USA) and different concentrations of primers (Table 3). Nuclease-free water was added to make the total volume $20 \mathrm{uL}$. The PCR reaction consisted of initial denaturation at $95^{\circ} \mathrm{C}$ for $5 \mathrm{~min}, 40$ cycles at $94{ }^{\circ} \mathrm{C}$ for $30 \mathrm{~s}$, $57^{\circ} \mathrm{C}$ for $30 \mathrm{~s}$ and $72{ }^{\circ} \mathrm{C}$ for $15 \mathrm{~s}$. 
Table 3. Primers used in this study.

\begin{tabular}{|c|c|c|c|c|}
\hline Gene & Primer Code & Concentration & Sequence $\left(5^{\prime}-3^{\prime}\right)$ & Fragment Length \\
\hline$\beta$-tubulin & AFtub_for & \multirow{2}{*}{$100 \mathrm{nM}$} & GGTCGTTACCTCACCTGCTCT & \multirow{2}{*}{$79 \mathrm{bp}$} \\
\hline ID 64852080 & AFtub_rev & & GGATGTTGCGCATCTGGT & \\
\hline aflR & aflR_for & \multirow[b]{2}{*}{$100 \mathrm{nM}$} & CGGCACAGCTTGTTCTGAGT & \multirow{2}{*}{$88 \mathrm{bp}$} \\
\hline ID 64848036 & aflR_rev & & GCATCGTCTCCACCTTCTTG & \\
\hline aflS & aflS_for & \multirow{2}{*}{$150 \mathrm{nM}$} & CTGGCAAAACTTGGGAATGG & \multirow{2}{*}{$103 \mathrm{bp}$} \\
\hline ID 64848035 & aflS_rev & & CACGAGGAAACGGAGTGATG & \\
\hline aflA & aflA_for & \multirow{2}{*}{$250 \mathrm{nM}$} & CATGCTGTTAACCCCCGACT & \multirow{2}{*}{$111 \mathrm{bp}$} \\
\hline ID 64848038 & aflA_rev & & AATTGGGCTAGGAAACCGGG & \\
\hline aflD & aflD_for & \multirow{2}{*}{$100 \mathrm{nM}$} & GCGCAAGTTCCACTTTGAGA & \multirow{2}{*}{$84 \mathrm{bp}$} \\
\hline ID 64848039 & aflD_rev & & CCTTGGTCGCCCATATCAGT & \\
\hline aflO & aflO_for & \multirow{2}{*}{$100 \mathrm{nM}$} & GTGCGGTGGTGCAACTATTC & \multirow{2}{*}{$71 \mathrm{bp}$} \\
\hline ID 64848026 & aflO_rev & & TCTCTCGGCCAGGAAGTCA & \\
\hline aflQ & aflQ_for & \multirow{2}{*}{$250 \mathrm{nM}$} & GCACCAACAATTCGGCTCTG & \multirow{2}{*}{$134 \mathrm{bp}$} \\
\hline ID 64848029 & aflQ_rev & & TGTGGAAGGGTGGAAGATGC & \\
\hline
\end{tabular}

The relative quantification of gene expression was established by using the $2^{-\Delta \Delta \mathrm{Ct}}$ method [87]. Statistical analysis was performed by using the $t$-test.

\subsection{Chemicals and Reagents}

The chemical standard of $\mathrm{AfB}_{1}$ (purity $>99 \%$ ) was supplied by Sigma-Aldrich (Milan, Italy). All solvents (HPLC grade) were purchased from VWR International Srl (Milan, Italy). The water Millipore Milli-Q system was purchased from Millipore (Bedford, MA, USA). Immunoaffinity columns (Aflatest ${ }^{\circledR} \mathrm{WB}$ ) were obtained from Vicam (Watertown, MA, USA). Glass microfiber filters (Whatman GF/A), paper filters (Whatman no. 4) and regenerated cellulose membrane filters $(\mathrm{RC}, 0.2 \mathrm{~mm})$ were obtained from Grace (Deerfield, IL, USA).

\subsection{Statistical Analysis}

Data were analyzed by one-way analysis of variance (ANOVA) and Tukey-Kramer multiple comparison test. The statistical analyses were performed using the GraphPad Instat 3.0 software (GraphPad Software, San Diego, CA, USA). Figures were drawn using OriginPro9.0 software (OriginLab Corporation, Northampton, MA, USA).

Supplementary Materials: The following supporting information can be downloaded at: https:/ /www. mdpi.com/article/10.3390/toxins14020086/s1, Figure S1: Chromatograms of aflatoxin B1 (AFB1) and B2 (AFB2) standards A) $5.0 \mathrm{ng} / \mathrm{mL}$ of AFB1 and $1 \mathrm{ng} / \mathrm{mL}$ AFB2 and B) $0.4 \mathrm{ng} / \mathrm{mL}$ of AFB1 and $0.08 \mathrm{ng} / \mathrm{mL}$ AFB2 in UPLC/PDA; Chromatograms of the diluted mycelium extract from the samples of Af-9 grown on CDP containing C) metabolites of T44 (AFB1 $0.04 \mu \mathrm{g} / \mathrm{g}$ ) and D) T60 (AFB1 $0.02 \mu \mathrm{g} / \mathrm{g})$.

Author Contributions: Conceptualization, C.A. and A.G.; methodology, X.R., M.T.B., A.G. and M.H.; data curation and analysis, X.R., M.T.B., M.H., A.G., Q.Z., P.L. and C.A.; writing-original draft preparation, X.R. and M.T.B.; writing-review and editing, C.A.; supervision, C.A., S.Z. and A.F.L.; funding acquisition, P.L., S.Z. and A.F.L. All authors have read and agreed to the published version of the manuscript.

Funding: This research was funded by the European Union's Horizon2020 Research and innovation program under Grant Agreement No.678781 (MycoKey) and by Shandong Key R \& D Plan (Major Scientific and Technological Innovation Project, 2019JZZY020903), Agricultural Science and Technology Innovation Project of Shandong Academy of Agricultural Sciences (37000021P11000111320E).

Institutional Review Board Statement: Not applicable.

Informed Consent Statement: Not applicable.

Data Availability Statement: The data presented in this study are available on request from the corresponding author. 
Conflicts of Interest: The authors declare that they have no competing interest.

\section{References}

1. Altomare, C.; Logrieco, A.F.; Gallo, A. Mycotoxins and Mycotoxigenic Fungi: Risk and Management. A Challenge for Future Global Food Safety and Security. Encycl. Mycol. 2021, 1, 64-93.

2. Bennett, J.W.; Klich, M. Clinical Microbiology Reviews. Mycotoxins 2003, 16, 497.

3. Craig, A.W. IARC monographs on the evaluation of the carcinogenic risk of chemicals to humans: International Agency for Research on Cancer. Food Chem. Toxicol. 1987, 25, 717.

4. IARC Working Group on the Evaluation of Carcinogenic Risks to Humans. Some Traditional Herbal Medicines, Some Mycotoxins, Naphthalene and Styrene. IARC Monogr. Eval. Carcinog. Risks Hum. 2002, 82, 1-556.

5. Klich, M.A. Aspergillus flavus: The major producer of aflatoxin. Mol. Plant Pathol. 2007, 8, 713-722. [CrossRef] [PubMed]

6. Amaike, S.; Keller, N.P. Aspergillus flavus. Annu. Rev. Phytopathol. 2011, 49, 107-133. [CrossRef]

7. Cotty, P.J. Virulence and cultural characteristics of two Aspergillus flavus strains pathogenic on cotton. Phytopathology 1989, 79, 808-814. [CrossRef]

8. Cotty, P.J. Aflatoxin-producing potential of communities of Aspergillus section Flavi from cotton producing areas in the United States. Mycol. Res. 1997, 101, 698-704. [CrossRef]

9. Abbas, H.K. Aflatoxin and fumonisin contamination of commercial corn (Zea mays) hybrids in Mississippi. J. Agric. Food Chem. 2002, 50, 5246-5254. [CrossRef]

10. Abbas, H.K.; Zablotowicz, R.M.; Locke, M.A. Spatial variability of Aspergillus flavus soil populations under different crops and corn grain colonization and aflatoxins. Can. J. Bot. 2004, 82, 1768-1775. [CrossRef]

11. Torres, A.M.; Barros, G.G.; Palacios, S.A.; Chulze, S.N.; Battilani, P. Review on pre- and post-harvest management of peanuts to minimize aflatoxin contamination. Food Res. Int. 2014, 62, 11-19. [CrossRef]

12. Horn, B.W.; Ramirez-Prado, J.H.; Carbone, I. The sexual state of Aspergillus parasiticus. Mycologia 2017, 101, 275-280. [CrossRef] [PubMed]

13. Egmond, H.P.V.; Jonker, M.A. Worldwide Regulations on Aflatoxins-The Situation in 2002. Toxin Rev. 2008, 119, 92-102. [CrossRef]

14. Ministry of Health of the People's Republic of China. GB2761-2011 National Food Safety Standard in Food. Limit of Mycotoxins; China Standard Press: Beijing, China, 2011.

15. EU Commision. Commission Regulation (EC). No 1881/2006 of 19 December 2006 setting maximum levels for certain contaminants in foodstuff. Off. J. Eur. Union 2006, L364, 5-24.

16. EU Commission. The Rapid Alert System for Food and Feed Annual Report. Food Saf. Brief. 2014, 16, 9-10.

17. Hka, C.; Xl, B.; Jing, J.A.; Fx, A. Current status of major mycotoxins contamination in food and feed in Africa. Food Control 2019, 110, 69-75.

18. Cotty, P.J.; Probst, C.; Jaime-Garcia, R. Etiology and Management of Aflatoxin Contamination. In Mycotoxins: Detection Methods, Management, Public Health and Agricultural Trade; Leslie, F., Ranajit, B., Eds.; CABI: Wallingford, UK, 2008; pp. $287-299$.

19. Payne, G.A. Process of contamination by aflatoxin producing fungi and their impacts on crops. In Mycotoxins in Agriculture and Food Safety; Sinha, K.K., Bhatnagar, D., Eds.; Marcel Dekker Inc.: New York, NY, USA, 1998.

20. Cotty, P.J.; Jaime-Garcia, R. Influences of climate on aflatoxin producing fungi and aflatoxin contamination. Int. J. Food Microbiol. 2007, 119, 109-115. [CrossRef]

21. Rajasekaran, K.; Cary, J.W.; Cleveland, T.E. Prevention of preharvest aflatoxin contamination through genetic engineering of crops. Mycotoxin Res. 2006, 22, 118-124. [CrossRef]

22. Cotty, P.J. Biocompetitive Exclusion of Toxigenic Fungi. In The Mycotoxin Factbook; Barug, D., Bhatnagar, D., Eds.; Wageningen Academic Publishers: Wageningen, The Netherlands, 2006; pp. 179-197.

23. Ehrlich, K.C.; Cotty, P.J. An isolate of Aspergillus flavus used to reduce aflatoxin contamination in cottonseed has a defective polyketide synthase. Appl. Microbiol. Biotechnol. 2004, 65, 473-478. [CrossRef]

24. Abbas, H.K.; Zablotowicz, R.M. Biocontrol of aflatoxin in corn by inoculation with non-aflatoxigenic Aspergillus flavus isolates. Biocontrol. Sci. Technol. 2007, 16, 437-449. [CrossRef]

25. Zhu, Y.; Hassan, Y.I.; Watts, C.; Zhou, T. Innovative technologies for the mitigation of mycotoxins in animal feed and ingredientsA review of recent patents. Anim. Feed Sci. Technol. 2016, 216, 19-29. [CrossRef]

26. Ehrlich, K.C.; Moore, G.G.; Mellon, J.E.; Bhatnagar, D. Challenges facing the biological control strategy for eliminating aflatoxin contamination. World Mycotoxin J. 2015, 8, 225-233. [CrossRef]

27. Pitt, J.I. The pros and cons of using biocontrol by competitive exclusion as a means for reducing aflatoxin in maize in Africa. World Mycotoxin J. 2019, 12, 103-112. [CrossRef]

28. Wilson, B.J. Toxins Other than Aflatoxins Produced by Aspergillus flavus. Bacteriol. Rev. 1966, 30, 478-484. [CrossRef]

29. Ehrlich, K.C. Non-aflatoxigenic Aspergillus flavus to prevent aflatoxin contamination in crops: Advantages and limitations. Front. Microbiol. 2014, 5, 50. [CrossRef] [PubMed]

30. Resnik, S.L.; González, H.H.L.; Pacin, A.M.; Viora, M.; Caballero, G.M.; Gros, E.G. Cyclopiazonic acid and aflatoxins production by Aspergillus flavus isolated from Argentinian corn. Mycotoxin Res. 1996, 12, 61-66. [CrossRef] 
31. Pinto, V.E.; Patriarca, A.; Locani, O.; Vaamonde, G. Natural co-occurrence of aflatoxin and cyclopiazonic acid in peanuts grown in Argentina. Food Addit. Contam. 2001, 18, 1017-1020. [CrossRef] [PubMed]

32. Siahmoshteh, F.; Hamidi-Esfahani, Z.; Spadaro, D.; Shams-Ghahfarokhi, M.; Razzaghi-Abyaneh, M. Unraveling the mode of antifungal action of Bacillus subtilis and Bacillus amyloliquefaciens as potential biocontrol agents against aflatoxigenic Aspergillus parasiticus. Food Control 2018, 89, 300-307. [CrossRef]

33. Kong, Q.; Chi, C.; Yu, J.; Shan, S.; Li, Q.; Li, Q.; Guan, B.; Nierman, W.C.; Bennett, J.W. The inhibitory effect of Bacillus megaterium on aflatoxin and cyclopiazonic acid biosynthetic pathway gene expression in Aspergillus flavus. Appl. Microbiol. Biotechnol. 2014, 98, 5161-5172. [CrossRef] [PubMed]

34. Palumbo, J.D.; O'Keeffe, T.L.; Abbas, H.K. Isolation of maize soil and rhizosphere bacteria with antagonistic activity against Aspergillus flavus and Fusarium verticillioides. J. Food Prot. 2007, 70, 1615-1621. [CrossRef]

35. Yang, X.; Zhang, Q.; Chen, Z.Y.; Liu, H.; Li, P. Investigation of Pseudomonas fluorescens strain 3JW1 on preventing and reducing aflatoxin contaminations in peanuts. PLoS ONE 2017, 12, e0178810. [CrossRef] [PubMed]

36. Ahlberg, S.; Joutsjoki, V.; Laurikkala, S.; Varmanen, P.; Korhonen, H. Aspergillus flavus growth inhibition by Lactobacillus strains isolated from traditional fermented Kenyan milk and maize products. Arch. Microbiol. 2017, 199, 457-464. [CrossRef]

37. Sangmanee, P.; Hongpattarakere, T. Inhibitory of multiple antifungal components produced by Lactobacillus plantarum K35 on growth, aflatoxin production and ultrastructure alterations of Aspergillus flavus and Aspergillus parasiticus. Food Control. 2014, 40, 224-233. [CrossRef]

38. Qaiser, S.; Ang, L.; Jing, Z.; Wu, M.; Li, G.; Tom, H.; Long, Y. Biocontrol of Aspergillus flavus on Peanut Kernels Using Streptomyces yanglinensis 3-10. Front. Microbiol. 2018, 9, 1049.

39. Verheecke, C.; Liboz, T.; Darriet, M.; Sabaou, N.; Mathieu, F. In vitro interaction of actinomycetes isolates with Aspergillus flavus: Impact on aflatoxins $\mathrm{B}_{1}$ and $\mathrm{B}_{2}$ production. Lett. Appl. Microbiol. 2014, 58, 597-603. [CrossRef] [PubMed]

40. Sultan, Y.; Magan, N. Impact of a Streptomyces (AS1) strain and its metabolites on control of Aspergillus flavus and aflatoxin $B_{1}$ contamination in vitro and in stored peanuts. Biocontrol. Sci. Technol. 2011, 21, 1437-1455. [CrossRef]

41. Medina-Córdova, N.; López-Aguilar, R.; Ascencio, F.; Castellanos, T.; Campa-Córdova, A.I.; Angulo, C. Biocontrol activity of the marine yeast Debaryomyces hansenii against phytopathogenic fungi and its ability to inhibit mycotoxins production in maize grain (Zea mays L.). Biol. Control 2016, 97, 70-79. [CrossRef]

42. Armando, M.R.; Dogi, C.A.; Rosa, C.A.R.; Dalcero, A.M.; Cavaglieri, L.R. Saccharomyces cerevisiae strains and the reduction of Aspergillus parasiticus growth and aflatoxin $\mathrm{B}_{1}$ production at different interacting environmental conditions, in vitro. Food. Addit. Contam. Part A 2012, 29, 1443-1449. [CrossRef]

43. Penna, M.L.; Etcheverry, M. Impact on growth and aflatoxin $\mathrm{B}_{1}$ accumulation by Kluyveromyces isolates at different water activity conditions. Mycopathologia 2006, 162, 347-353. [CrossRef]

44. Hua, S.S.T.; Baker, J.L.; Flores-Espiritu, M. Interactions of saprophytic yeasts with a nor mutant of Aspergillus flavus. Appl. Environ. Microbiol. 1999, 65, 2738-2740. [CrossRef]

45. Woo, S.L.; Ruocco, M.; Vinale, F.; Nigro, M.; Marra, R.; Lombardi, N.; Pascale, A.; Lanzuise, S.; Manganiello, G.; Lorito, M. Trichoderma-based Products and their Widespread Use in Agriculture. Open Mycol. J. 2014, 8, 71-126. [CrossRef]

46. Harman, G.E.; Howell, C.R.; Viterbo, A.; Chet, I.; Lorito, M. Trichoderma species-opportunistic, avirulent plant symbionts. Nat Rev. Microbiol. 2004, 2, 43-56. [CrossRef]

47. Altomare, C.; Norvell, W.A.; Björkman, T.; Harman, G.E. Solubilization of Phosphates and Micronutrients by the Plant-Growth Promoting and Biocontrol Fungus Trichoderma harzianum Rifai 1295-22. Appl. Environ. Microbiol. 1999, 65, 2926-2933. [CrossRef]

48. López-Bucio, J.; Pelagio-Flores, R.; Herrera-Estrella, A. Trichoderma as biostimulant: Exploiting the multilevel properties of a plant beneficial fungus. Sci. Hortic. 2015, 196, 109-123. [CrossRef]

49. Howell, C.R. Mechanisms Employed by Trichoderma Species in the Biological Control of Plant Diseases: The History and Evolution of Current Concepts. Plant Dis. 2003, 87, 4-10. [CrossRef]

50. Hermosa, R.; Cardoza, R.E.; Rubio, M.B.; Gutiérrez, S.; Monte, E. Secondary metabolism and antimicrobial metabolites of Trichoderma. In Biotechnology and Biology of Trichoderma; Gupta, V.K., Schmoll, M., Eds.; Elsevier: Amsterdam, The Netherlands, 2014; pp. 125-137.

51. Wicklow, D.T. Interference competition. In The Fungal Community-Its Organization and Role in the Ecosystem; Carroll, G.C., Wicklow, D.T., Eds.; Marcel Dekker: New York, NY, USA, 1992; pp. 265-274.

52. Whipps, J.M. Effect of media on growth and interactions between a range of soil-borne glasshouse pathogens and antagonistic fungi. New Phytol. 1987, 107, 127-142. [CrossRef]

53. Mostafa, A.A. Antagonistic Activities of Some Fungal Strains against the Toxigenic Aspergillus flavus Isolate and its Aflatoxins Productivity. J. Pure Appl. Microbiol. 2013, 7, 169-178.

54. Calistru, C.; McLean, M.; Berjak, P. In vitro studies on the potential for biological control of Aspergillus flavus and Fusarium moniliforme by Trichoderma species-A study of the production of extracellular metabolites by Trichoderma species. Mycopathologia 1997, 137, 115-124. [CrossRef] [PubMed]

55. Xing, F.; Wang, L.; Liu, X.; Selvaraj, J.N.; Wang, Y.; Zhao, Y.; Liu, Y. Aflatoxin B ${ }_{1}$ inhibition in Aspergillus flavus by Aspergillus niger through down-regulating expression of major biosynthetic genes and $\mathrm{AFB}_{1}$ degradation by atoxigenic A. flavus. Int. J. Food Microbiol. 2017, 256, 1-10. [CrossRef] [PubMed] 
56. Cotty, P.J.; Bayman, P. Competitive exclusion of a toxigenic strain of Aspergillus flavus by an atoxigenic strain. Phytopathology 1993, 83, 1283-1287. [CrossRef]

57. Lorito, M.; Woo, S.L.; Harman, G.E.; Monte, E. Translational research on Trichoderma: From 'omics to the field. Annu. Rev. Phytopathol. 2010, 48, 395-417. [CrossRef]

58. Gajera, H.P.; Savaliya, D.D.; Patel, S.V.; Golakiya, B.A. Trichoderma viride induces pathogenesis related defense response against rot pathogen infection in groundnut (Arachis hypogaea L.). Infect. Genet. Evol. 2015, 34, 314-325. [CrossRef]

59. Mastouri, F.; Björkman, T.; Harman, G.E. Trichoderma harzianum Enhances Antioxidant Defense of Tomato Seedlings and Resistance to Water Deficit. Mol. Plant-Microbe Interact. 2012, 25, 1264-1271. [CrossRef]

60. Contreras-Cornejo, H.A.; Viveros-Bremauntz, F.; del-Val, E.; Macías-Rodríguez, L.; López-Carmona, D.A.; Alarcón, A.; González-Esquivel, C.E.; Larsen, J. Alterations of foliar arthropod communities in a maize agroecosystem induced by the root-associated fungus Trichoderma harzianum. J. Pest. Sci. 2021, 94, 363-374. [CrossRef]

61. Coppola, M.; Cascone, P.; Di Lelio, I.; Woo, S.L.; Lorito, M.; Rao, R.; Pennacchio, F.; Guerrieri, E.; Digilio, M.C. Trichoderma atroviride P1 Colonization of Tomato Plants Enhances Both Direct and Indirect Defense Barriers Against Insects. Front. Physiol. 2019, 10, 813. [CrossRef]

62. Anjaiah, V.; Thakur, R.P.; Koedam, N. Evaluation of bacteria and Trichoderma for biocontrol of pre-harvest seed infection by Aspergillus flavus in groundnut. Biocontrol. Sci. Technol. 2006, 16, 431-436. [CrossRef]

63. Sivparsad, B.J.; Laing, M.D. Pre-harvest silk treatment with Trichoderma harzianum reduces aflatoxin contamination in sweetcorn. J. Plant Dis. Prot. 2016, 123, 285-293. [CrossRef]

64. Kifle, M.H.; Yobo, K.S.; Laing, M.D. Biocontol of Aspergillus flavus in groundnut using Trichoderma harzanium stain kd. J. Plant Dis. Prot. 2017, 124, 51-56. [CrossRef]

65. Dania, V.O.; Eze, S.E. Using Trichoderma Species in Combination with Cattle Dung as Soil Amendment Improves Yield and Reduces Pre-Harvest Aflatoxin Contamination in Groundnut. AGRIVITA J. Agric. Sci. 2020, 42, 449-461. [CrossRef]

66. Debnath, S.; Kabir, S.E. Antagonistic Behavior of Trichoderma harzianum against Aspergillus flavus and A. niger. Indian J. Fundam. Appl. Life Sci. 2017, 7, 1-4.

67. Gachomo, E.W.; Kotchoni, S.O. The Use of Trichoderma harzianum and T. viride as Potential Biocontrol Agents against Peanut Microflora and Their Effectiveness in Reducing Aflatoxin Contamination of Infected Kernels. Biotechnology 2008, 7, $439-447$. [CrossRef]

68. Schroeder, H.W. Effect of corn steep liquor on mycelial growth and aflatoxin production in Aspergillus parasiticius. Appl. Microbiol. 1966, 14, 381-385. [CrossRef] [PubMed]

69. Yu, J.; Mohawed, S.M.; Bhatnagar, D.; Cleveland, T.E. Substrate-induced lipase gene expression and aflatoxin production in Aspergillus parasiticus and Aspergillus flavus. J. Appl. Microbiol. 2003, 95, 1334-1342. [CrossRef]

70. Huang, Z.; White, D.G.; Gary, A.P. Corn Seed Proteins Inhibitory to Aspergillus flavus and Aflatoxin Biosynthesis. Phytopathology 1997, 87, 622-627. [CrossRef] [PubMed]

71. Caceres, I.; Khoury, A.A.; Khoury, R.E.; Lorber, S.; Oswald, I.P.; Khoury, A.E.; Atoui, A.; Puel, O.; Bailly, J.D. Aflatoxin Biosynthesis and Genetic Regulation: A Review. Toxins 2020, 12, 150. [CrossRef] [PubMed]

72. Gallo, A.; Solfrizzo, M.; Epifani, F.; Panzarini, G.; Perrone, G. Effect of temperature and water activity on gene expression and aflatoxin biosynthesis in Aspergillus flavus on almond medium. Int. J. Food Microbiol. 2016, 217, 162-169. [CrossRef]

73. Chang, P.K. The Aspergillus parasiticus protein AFLJ interacts with the aflatoxin pathway-specific regulator AFLR. Mol. Genet. Genom. 2003, 268, 711-719. [CrossRef]

74. Price, M.S.; Yu, J.; Nierman, W.C.; Kim, H.; Pritchard, B.; Jacobus, C.A.; Bhatnagar, D.; Cleveland, T.E.; Payne, G.A. The aflatoxin pathway regulator AflR induces gene transcription inside and outside of the aflatoxin biosynthetic cluster. FEMS Microbiol. Lett. 2006, 255, 275-279. [CrossRef]

75. Caceres, I.; Snini, S.P.; Puel, O.; Mathieu, F. Streptomyces Roseolus, a promising biocontrol agent against Aspergillus flavus, the main aflatoxin $\mathrm{B}_{1}$ producer. Toxins 2018, 10, 442. [CrossRef] [PubMed]

76. Vanhoutte, I.; Audenaert, K.; De Gelder, L. Biodegradation of mycotoxins: Tales from known and unexplored worlds. Front. Microbiol. 2016, 7, 561. [CrossRef]

77. Khonga, E.B.; Kaundat, C.C.; Hillocks, R.J. Biocontrol of Sclerotium rolfsii Sacc. in peanuts (Arachis hypogaea L.) by Trichoderma harzianum Rifai in Malawi. Malawi J. Sci. Technol. 1998, 4, 51-62. [CrossRef]

78. Ganuza, M.; Pastor, N.; Erazo, J.; Andrés, J.; Reynoso, M.M.; Rovera, M.; Torres, A.M. Efficacy of the biocontrol agent Trichoderma harzianum ITEM 3636 against peanut smut, an emergent disease caused by Thecaphora frezii. Eur. J. Plant. Pathol. 2018, 151, 257-262. [CrossRef]

79. Diener, U.L.; Cole, R.J.; Sanders, T.H.; Payne, G.A.; Lee, L.S.; Klich, M.A. Epidemiology of Aflatoxin Formation by Aspergillus flavus. Ann. Rev. Phytopathol. 1987, 25, 249-270. [CrossRef]

80. Gams, W.; Bissett, J. Morphology and identification of Trichoderma. In Trichoderma and Gliocladium; Kubicek, C.P., Harman, G.E., Eds.; CRC Press: London, UK, 1998; Volume 1, pp. 3-34.

81. Fanelli, F.; Liuzzi, V.C.; Logrieco, A.F.; Altomare, C. Genomic characterization of Trichoderma atrobrunneum (T. harzianum species complex) ITEM 908: Insight into the genetic endowment of a multi-target biocontrol strain. BMC Genom. 2018, 19, 662. [CrossRef]

82. Chaverri, P.; Branco-Rocha, F.; Jaklitsch, W.; Gazis, R.; Degenkolb, T.; Samuels, G.J. Systematics of the Trichoderma harzianum species complex and the re-identification of commercial biocontrol strains. Mycologia 2015, 107, 558-590. [CrossRef] 
83. Marzano, M.; Gallo, A.; Altomare, C. Improvement of biocontrol efficacy of Trichoderma harzianum vs. Fusarium oxysporum f. sp. lycopersici through UV-induced tolerance to fusaric acid. Biol. Control 2013, 67, 397-408. [CrossRef]

84. Altomare, C.; Perrone, G.; Zonno, M.C.; Evidente, A.; Pengue, R.; Franti, F.; Polonelli, L. Biological characterization of fusapyrone and deoxyfusapyrone, two bioactive secondary metabolites of Fusarium semitectum. J. Nat. Prod. 2000, 63, 1131-1135. [CrossRef]

85. Fani, S.R.; Moradi, M.; Probst, C.; Zamanizadeh, H.R.; Mirabolfathy, M.; Haidukowski, M.; Logrieco, A.F. A critical evaluation of cultural methods for the identification of atoxigenic Aspergillus flavus isolates for aflatoxin mitigation in pistachio orchards of Iran. Eur. J. Plant Pathol. 2014, 140, 631-642. [CrossRef]

86. Branà, M.T.; Cimmarusti, M.T.; Haidukowski, M.; Logrieco, A.F.; Altomare, C. Bioremediation of aflatoxin B1-contaminated maize by king oyster mushroom (Pleurotus eryngii). PLoS ONE 2017, 12, e0182574. [CrossRef]

87. Livak, K.J.; Schmittgen, T.D. Analysis of relative gene 428 expression data using Real-Time Quantitative PCR and the $2^{-\Delta \Delta C t}$ method. Methods 2001, 25, 402-408. [CrossRef] 